Received: 17 November 2016 Accepted: 27 March 2017 Published online: 28 April 2017

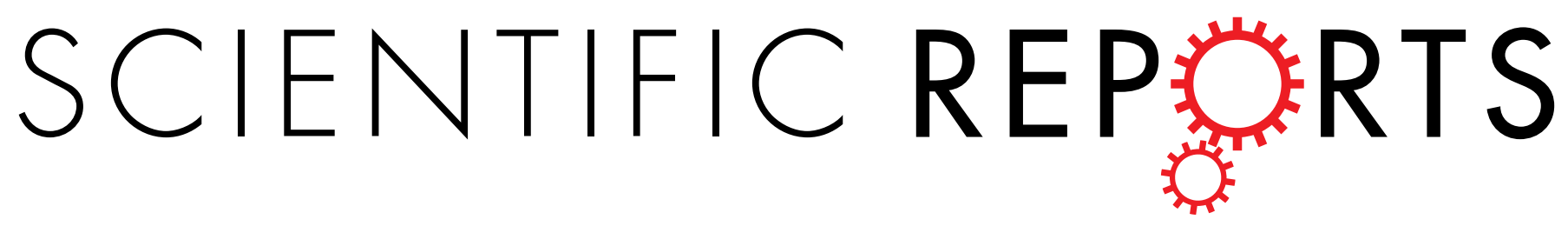

\title{
OPEN Calcium-Sensing Receptor Antagonist NPS 2143 Restores Amyloid Precursor Protein Physiological Non-Amyloidogenic Processing in A $\beta$-Exposed Adult Human Astrocytes
}

\begin{abstract}
Anna Chiarini ${ }^{1}$, Ubaldo Armato $\mathbb{D}^{1}$, Daisong Liv ${ }^{2}$ \& Ilaria Dal Prà ${ }^{1}$
Physiological non-amyloidogenic processing (NAP) of amyloid precursor holoprotein (hAPP) by $\alpha$-secretases (e.g., ADAM10) extracellularly sheds neurotrophic/neuroprotective soluble (s)APP $\alpha$ and precludes amyloid- $\beta$ peptides (A $\beta$ s) production via $\beta$-secretase amyloidogenic processing (AP). Evidence exists that $A \beta s$ interact with calcium-sensing receptors (CaSRs) in human astrocytes and neurons, driving the overrelease of toxic $A \beta_{42} / A \beta_{42}$-os (oligomers), which is completely blocked by CaSR antagonist (calcilytic) NPS 2143. Here, we investigated the mechanisms underlying NPS 2143 beneficial effects in human astrocytes. Moreover, because Alzheimer's disease (AD) involves neuroinflammation, we examined whether NPS 2143 remained beneficial when both fibrillary (f)A $\beta_{25-35}$ and a microglial cytokine mixture (CMT) were present. Thus, hAPP NAP prevailed over AP in untreated astrocytes, which extracellularly shed all synthesized sAPP $\alpha$ while secreting basal $A \beta_{40 / 42}$ amounts. Conversely, $f A \beta_{25-35}$ alone dramatically reduced sAPPo extracellular shedding while driving $A \beta_{42} / A \beta_{42}$-os oversecretion that CMT accelerated but not increased, despite a concurring hAPP overexpression. NPS 2143 promoted hAPP and ADAM10 translocation to the plasma membrane, thereby restoring SAPP $\alpha$ extracellular shedding and fully suppressing any $A \beta_{42} / A \beta_{42}$-os oversecretion, but left hAPP expression unaffected. Therefore, as anti-AD therapeutics calcilytics support neuronal viability by safeguarding astrocytes neurotrophic/neuroprotective sAPP $\alpha$ shedding, suppressing neurons and astrocytes $A \beta_{42} / A \beta_{42}-$ os build-up/secretion, and remaining effective even under AD-typical neuroinflammatory conditions.
\end{abstract}

Alzheimer's disease (AD) causes dementia in tens of millions of people worldwide ${ }^{1}$. The typical markers of AD are senile plaques, i.e., accumulations of amyloid- $\beta$ peptides (A $\beta s$ ) in the neuropil; neurofibrillary tangles (NFTs), i.e., insoluble clusters of hyperphosphorylated Tau proteins inside neurons; the loss of synaptic contacts; neurotoxicity; increased cell death in neurons and oligodendrocytes; activated astrocytes and microglia; chronic neuroinflammation; cerebrovascular damage; and blood-brain barrier dysfunction ${ }^{2-4}$. These markers are present in extended cortical areas up to fifteen years before the onset of any memory or cognition decline $e^{2,5,6}$.

Amyloid precursor holoprotein (hAPP)'s pathophysiological relevance in AD is notorious ${ }^{7,8}$. Human hAPP and its mammalian homologues AP-like protein 1 (APLP1) and 2 (APLP2) are integral transmembrane proteins that promote cell adhesion by homo- or hetero-dimerization or functioning as receptors ${ }^{9}$. Their manifold physiological activities include the modulation of cell survival, axonal growth, synaptogenesis, synaptic plasticity, and neuronal excitability ${ }^{7,8,10}$. hAPP is synthesized in the endoplasmic reticulum (ER), post-translationally modified by $\mathrm{N}$ - and $\mathrm{O}$-linked glycosylation, and transported along the secretory pathway to the cell surface ${ }^{11}$.

${ }^{1}$ Human Histology \& Embryology Unit, Medical School, University of Verona, Verona, Venetia, Italy. ${ }^{2}$ The Third Xiangya Hospital of Central South University, Department of Plastic Surgery, Changsha, Hunan, China. Correspondence and requests for materials should be addressed to A.C. (email: anchiari@gmail.com) or I.D. (email: ippdalpra@gmail.com) 
Importantly, hAPP undergoes proteolysis via two pathways: amyloidogenic processing (AP) and non-amyloidogenic processing (NAP). In AP, BACE ( $\beta$-site APP cleaving enzyme) $1 / \beta$-secretase, a membrane-bound aspartyl protease, cleaves the N-terminus of the hAPP A $\beta$ domain in the trans-Golgi network (TGN) and, following endocytosis, in the endosomal/lysosomal system ${ }^{11-15}$, thereby releasing (shedding) a pro-apoptotic soluble (s)APP $\beta$ ectodomain ${ }^{14,15}$. The membrane-bound $\gamma$-secretase complex, comprising presenilins 1 (PS1) and 2 (PS2), cleaves the C99 or CTF $\beta$ (99 amino acid C-terminal fragment) of membrane-bound hAPP, producing ( $i) \mathrm{A} \beta$ s and (ii) the hAPP intracellular domain (AICD) peptide, which might play a transcriptional role ${ }^{16-19}$. Therefore, mutations in the genes encoding hAPP, PS1 or PS2 drive early-onset familial AD (EOFAD; $<3 \%$ cases) by driving the surplus production/release of $\mathrm{A} \beta \mathrm{s}$, which then cluster as variously sized toxic oligomers $(\mathrm{A} \beta$-os $)$ or polymers (fibrils) $)^{19}$. Conversely, the aetiologic factors underlying the prevailing $(>95 \%$ cases) late-onset (sporadic) AD (LOAD) cases are likely manifold, slow-acting, and less defined than those underlying EOFAD. Only heterozygous or homozygous apolipoprotein E (APOE) $\varepsilon 4$ alleles and TREM-2 mutations, chiefly $\mathrm{R} 47 \mathrm{H}$, aid the onset and progression of $\mathrm{LOAD}^{20}$. Therefore, various vascular and metabolic shortcomings interact to hinder the brain's clearance of the $\mathrm{A} \beta$ s that accumulate in the neuropil ${ }^{2-4,21}$. However, even in LOAD, neuropil-clogging $\mathrm{A} \beta \mathrm{s}$ drive, via $\mathrm{A} \beta \bullet \mathrm{CaSR}$ (calcium-sensing receptor) signalling, increased AP of hAPP, causing the surplus production/release of $A \beta_{42} / A \beta_{42}$-os from both astrocytes and neurons. Such $A \beta$ s devastatingly spread from the hippocampus to a wide range of upper cortical areas ${ }^{22-24}$.

Under physiological conditions, hAPP NAP typically prevails: hAPP is mostly cleaved between amino acids 612 and 613 within the $\mathrm{A} \beta$ domain by $\alpha$-secretase, which impedes any $\mathrm{A} \beta$ production ${ }^{7,19}$. Physiologically, ADAM10 (a disintegrin and metalloprotease domain-containing protein 10) is the principal hAPP $\alpha$-secretase in neurons ${ }^{25}$, which acts mainly at the cell surface and within the TGN ${ }^{26,27}$ and sheds the soluble (s)APP $\alpha$ ectodomain from hAPP 25,28 .

sAPP $\alpha$ acts as a neurotrophic and neuroprotective compound in brain ischaemic, traumatic, and excitotoxic injuries ${ }^{29,30}$. Interestingly, sAPP $\alpha$ levels decrease in the cerebrospinal fluids of AD patients ${ }^{31}$. This decrease implies a partial loss of sAPP $\alpha$ activity, resulting in reduced plasticity, connectivity, and synaptic signalling, all of which favour the demise of neurons that occurs in $\mathrm{AD}^{10,31}$. The ectodomains of both membrane-bound hAPP and shed sAPP $\alpha$ play neuroprotective roles in vitro ${ }^{25,30,32-37}$, although the receptor(s) and signalling pathway(s) involved remain unclear. Moreover, we know little about the complex mechanisms that modulate hAPP NAP and AP balance, particularly in cortical untransformed human neurons and astrocytes; however, hAPP intracellular trafficking, $\gamma$-secretase ${ }^{38}$, and $\alpha$-secretase ${ }^{27,39}$ are involved. Undoubtedly, clarification of the mechanisms involved would impact our understanding of $\mathrm{AD}$ pathophysiology and therapy.

Previously, most studies focused on neurons as the main sites of BACE1/ $\beta$-secretase expression ${ }^{40,41}$ and $\mathrm{A} \beta$ production in mouse brains $s^{3,42,43}$. Activated microglia are the second most investigated brain cell type, as they engulf fibrillar and soluble $A \beta s$, promote $A \beta$ clumping inside senile plaques, secrete proinflammatory cytokines, and overrelease toxic nitric oxide $(\mathrm{NO})$ and reactive oxygen species (ROS) ${ }^{3,4,44}$. Conversely, astrocytes were believed to scavenge, accumulate, proteolyze, and release $A \beta s$, thereby promoting the build-up of glial fibrillary acidic protein (GFAP)-rich senile plaques ${ }^{45}$. However, recent evidence shows that astrocytes also play pivotal roles in the onset and progression of human $\mathrm{AD}$, being more numerous than neurons, establishing extended inter-astrocyte networks via gap junctions, forming teams with client neurons, wrapping tripartite synapses, sheltering neurons from environmental toxins, and exchanging with them physiological and pathological (e.g., A $\beta$ s) metabolic compounds ${ }^{46-48}$. Eventually, the benefits of the neuron-sustaining activities of astrocytes vanish when the $\mathrm{A} \beta$-clearing activity becomes too intense $\mathrm{e}^{45-49}$.

Blasko et al. ${ }^{50}$ first reported that human astrocytes produce $A \beta_{40}$ and $A \beta_{42}$ upon exposure to pairs of microglial proinflammatory cytokines, such as interferon (IFN) $-\gamma$ plus tumour necrosis factor (TNF)- $\alpha$ or interleukin (IL)-1 $\beta^{44}$. Activated cortical astrocytes from neonatal mice also exhibited elevated levels of hAPP, BACE1 activity, and $A \beta_{40}$ secretion when challenged with IFN- $\gamma+$ TNF- $\alpha$ or sA $\beta_{42}$ or $\mathrm{fA} \beta_{42}{ }^{51}$. These findings suggested that neuroinflammation might drive $\mathrm{A} \beta$ production/release from human and rodent astrocytes, thus increasing the $\mathrm{A} \beta$ load in the brain. Importantly, cortical untransformed adult human astrocytes synthesize, accumulate, and secrete increased amounts of endogenous $A \beta_{42} / A \beta_{42}$-os when exposed to exogenous $f A \beta_{25-35}$ or sA $\beta_{25-35}{ }^{22-24,52}$. Additionally, exogenous $A \beta$ s specifically bind plasma membrane CaSRs and activate their manifold signalling, which drives repeated cycles of exogenous $\mathrm{A} \beta \mathrm{s} \Rightarrow$ endogenous $\mathrm{A} \beta 42$ production/secretion in human cortical astrocytes and neurons ${ }^{22-24,53}$.

CaSRs, which are a family C G-protein-coupled receptors, quickly recognize changes in extracellular $\mathrm{Ca}^{2+}$ levels $\left[\mathrm{Ca}^{2+}\right]_{\mathrm{e}}$, yet also bind other cations such as polyamines, amino glycoside antibiotics, and $\mathrm{A} \beta \mathrm{s}^{22-24,53,54}$. The intracellular domains of CaSRs interact with various $\mathrm{G}$-proteins to modulate a complex set of signalling activities, including ( $i$ ) protein kinases (AKT, PKCs, MAPKs); (ii) phospholipases (A2, C, and D); (iii) transcription factors (TFs); (iv) second messenger production (e.g., cAMP); and ( $v$ ) $\mathrm{Ca}^{2+}$ influx via TRPC6-encoded receptor-operated channels ${ }^{55,56}$. All cells in the central nervous system (CNS) express CaSRs, though expression levels vary by region, with particularly high expression in the hippocampus ${ }^{57}$. In addition, proliferatively quiescent untransformed adult human astrocytes express functional CaSRs more strongly than growing astrocytes independent of $\left[\mathrm{Ca}^{2+}\right]_{\mathrm{e}}$ changes $^{58}$. Aside from regulating general $\mathrm{Ca}^{2+}$ homeostasis ${ }^{55}$, CaSRs play additional important roles in the CNS ${ }^{24,59}$.

Altered expression or dysfunction of CaSRs also impacts CNS diseases, such as AD and ischaemia/hypoxia/ stroke, by modulating amyloidogenesis, glial activation, outward $\mathrm{K}^{+}$channel fluxes, $\mathrm{NO}$ and VEGF-A overproduction, and neuronal death $22-24,57,60-63$.

The use of non-tumorigenic cortical adult human astrocytes and postnatal HCN-1A neurons as in vitro preclinical models has revealed a novel pathological interaction by which exogenous $A \beta s$ bind and activate $\mathrm{CaSRs}^{22-24}$. In addition to the transient overexpression of the CaSR, this interaction leads to the surplus production, accumulation and secretion of $A \beta_{42}$-os from both astrocytes and neurons, coupled with increased cell death 
(a)

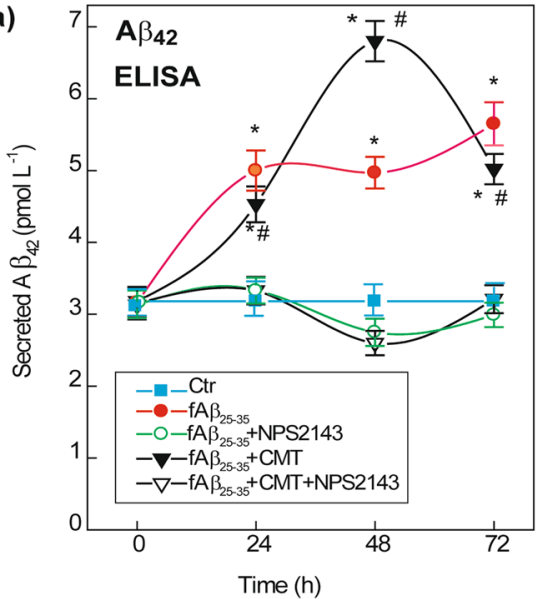

(c)

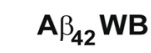

$\mathrm{fA} \beta_{25-35}+\mathrm{CMT} \quad \mathrm{fA} \beta_{25-35}+\mathrm{CMT}+\mathrm{NPS} 2143$ $\begin{array}{lllllllll}0 & 24 & 48 & 72 & 0 & 24 & 48 & 72 & \mathrm{~h}\end{array}$

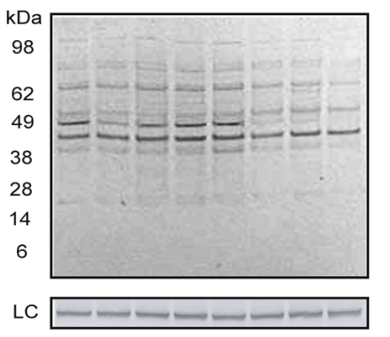

(d)

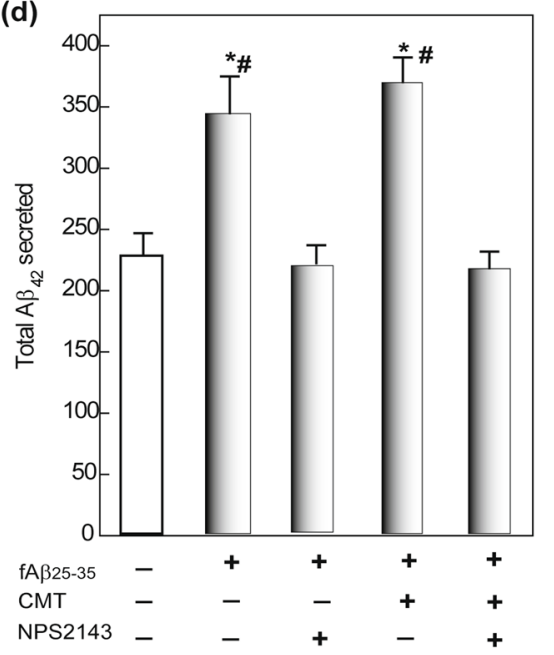

(b)
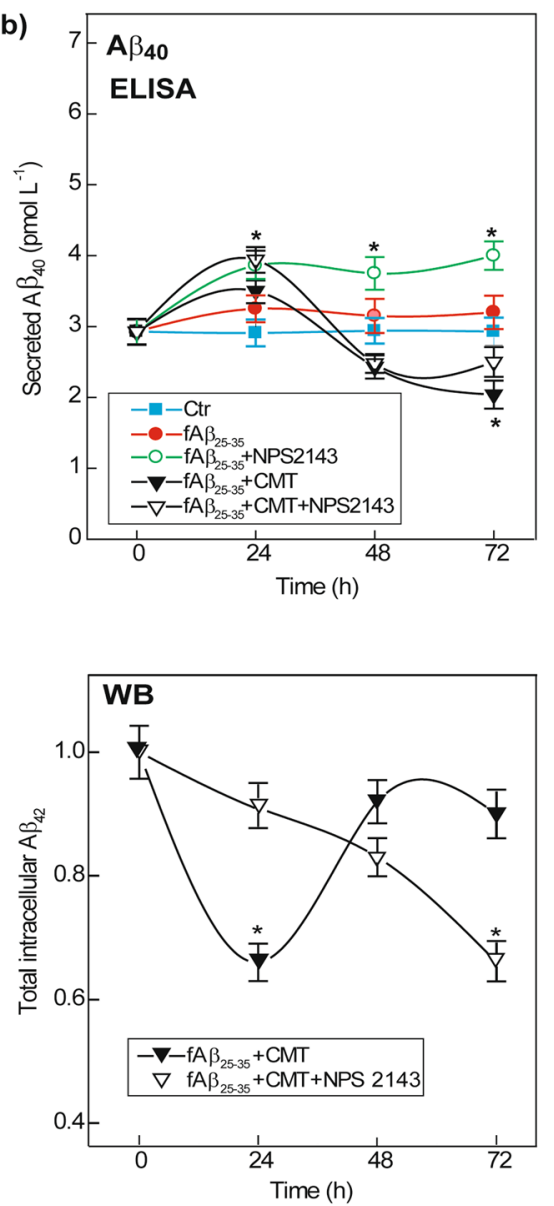

(e)

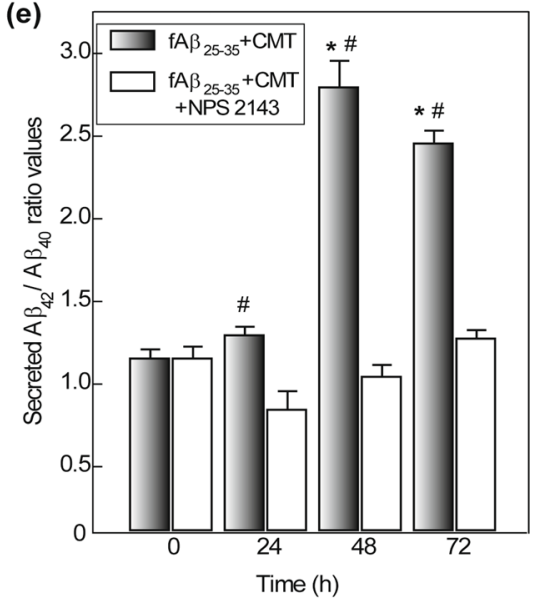

Figure 1. Changes in human astrocytes' secreted and intracellular amounts of endogenous $A \beta_{42}$ and $A \beta_{40}$. (a) $A \beta_{42}$ peptides secreted amounts increase after an exposure to $f A \beta_{25-35} \pm C M T$, but stay unchanged when NPS 2143 is also added. Points on the curves are means \pm SEM of 3-5 independent experiments;

$\mathrm{fA}_{25-35}+\mathrm{CMT} \pm \mathrm{NPS} 2143$ : one-way ANOVA analysis of the complete data set $F=140.805, \mathrm{P}<0.001$.

Bonferroni t-test: comparisons of each treated group versus 0 -h group (controls): ${ }^{*} \mathrm{P}<0.05$; pair-wise comparisons between corresponding treatments \pm NPS 2143 at each time point: ${ }^{*} \mathrm{P}<0.05$. (b) Changes in $A \beta_{40}$ released amounts according to the treatments. Points on the curves are means \pm SEM of 3-5 independent experiments; $\mathrm{fA} \beta_{25-35}+\mathrm{CMT} \pm \mathrm{NPS} 2143$ : one-way ANOVA analysis of the complete data set $F=13.871$, $\mathrm{P}<0.001$. Bonferroni t-test: comparisons of each treated group versus 0 -h group (controls): $* \mathrm{P}<0.05$. (c) Left panel. Typical immunoblot revealing the changes in intracellularly accumulated $A \beta_{42} / A \beta_{42}$-os versus untreated controls according to treatments. LC, loading control. Right panel. Densitometric evaluations of the whole sets of intracellular $A \beta_{42}$ bands at each time point. Points on the curves are means \pm SEM of 3 independent experiments, with control values normalized as 1.0. One-way ANOVA analysis of the complete data set $F=3.933, \mathrm{P}<0.012$. Bonferroni t-test: comparisons of each treated group versus 0 -h group (controls): $* \mathrm{P}<0.05$. 
(d) Alterations in total 0-to-72-h amounts of secreted $\mathrm{A} \beta_{42}$ according to treatments. Bars are means \pm SEM of 5 independent experiments. One-way ANOVA analysis of the complete data set $F=13.248, \mathrm{P}<0.001$. Bonferroni $t$-test: comparisons of each treated group versus 0 -h group (controls): $* \mathrm{P}<0.05$; pair-wise comparisons between corresponding treatments \pm NPS 2143 : ${ }^{\#} \mathrm{P}<0.05$. (e) Changes in secreted $\mathrm{A} \beta_{42} / \mathrm{A} \beta_{40}$ ratio values according to treatments in the conditioned growth media of astrocytes. Bars are means \pm SEM of 3 independent experiments. One-way ANOVA analysis of the complete data set $F=73.769, \mathrm{P}<0.001$; Bonferroni t-test: comparisons of each treated group versus 0 -h group (controls): $* \mathrm{P}<0.05$; pair-wise comparisons between corresponding treatments \pm NPS 2143 at each time point: ${ }^{\#} \mathrm{P}<0.05$.

among the latter. The CaSR agonist NPS R-568 increases $A \beta_{42}$-os release from human cortical astrocytes, mimicking the effect of $A \beta_{25-35} \bullet$ CaSR signalling ${ }^{22-24}$. Simultaneously, $A \beta$-os $\bullet$ CaSR signalling in astrocytes induces the surplus production/release of NO and VEGF-A ${ }^{58,61}$. These findings suggested that various phenylalkylamines, acting as allosteric CaSR antagonists (calcilytics; e.g., NPS 89636 and NPS 2143) capable of shifting the CaSR response curve to changes in $\left[\mathrm{Ca}^{2+}\right]_{e}^{54,64}$, may be potential AD therapeutics. Calcilytic NPS 2143 suppressed all aforementioned neurotoxic effects elicited by exogenous $\mathrm{A} \beta_{25-35} \bullet \mathrm{CaSR}$ signalling and fully preserved neuronal viability ${ }^{22-24}$.

Given the potential value for AD therapy, in this work, we explored for the first time the mechanisms underlying the beneficial effects of NPS 2143 in human astrocytes, particularly the effects of A $\beta \bullet C a S R$ signalling on the NAP of hAPP and the modulation of such effects by a calcilytic. Moreover, as AD progression in the human brain is coupled with diffuse, chronic neuroinflammation ${ }^{65}$, we sought to determine whether a calcilytic might still antagonize the noxious effects of $\mathrm{fA} \beta_{25-35} \bullet \mathrm{CaSR}$ signalling when a microglial cytokine mixture trio (CMT; i.e., IFN- $\gamma$, TNF- $\alpha$, and IL-1 $\beta$ ) was also administered ${ }^{58}$. The results reported herein further strengthen our view ${ }^{22-24}$ that calcilytics embody a novel class of anti-AD therapeutics that effectively maintain the physiological shedding of neurotrophic and neuroprotective sAPP $\alpha$ by human astrocytes, as well as fully antagonizing all $\mathrm{A} \beta_{25-35} \bullet \mathrm{CaSR}$ signalling-elicited neurotoxic effects, even in the presence of microglial proinflammatory cytokines.

\section{Results}

The specific involvement of CaSRs in the following studies was shown by the inhibitory effects of a highly selective antagonist, NPS 2143, on the NO release and cAMP levels elicited by various treatments (see Supplementary Information and Fig. S1). The reversemer peptide $\mathrm{A} \beta_{35-25}$ was always ineffective (not shown).

Calcilytic NPS 2143 suppresses $A \beta_{42} / A \beta_{42}$-os oversecretion driven by fA $\beta_{25-35} \pm$ CMT. Secreted and intracellular $A \beta_{42}$ levels. The amount of endogenous $A \beta_{42} / A \beta_{42}$-os released from $\mathrm{fA} \beta_{25-35}$-exposed human astrocytes rose quickly at first and then more slowly. Co-treatment with CMT hastened the secretion of endogenous $\mathrm{A} \beta_{42} / \mathrm{A} \beta_{42}$-os, which peaked at $48 \mathrm{~h}$ (Fig. 1a). However, CMT addition only marginally increased the total amount of $A \beta_{42} / A \beta_{42}$-os secreted over 72 h versus $f A \beta_{25-35}$ alone (Fig. 1d). NPS 2143 treatment fully suppressed the surplus secretion of endogenous $A \beta_{42} / A \beta_{42}$-os caused by fA $\beta_{25-35} \pm \mathrm{CMT}$, maintaining the total amount of $\mathrm{A} \beta_{42} / \mathrm{A} \beta_{42}$-os secreted from $0 \mathrm{~h}$ to $72 \mathrm{~h}$ at control levels (Fig. 1a,d).

In contrast, $\mathrm{fA} \beta_{25-35}+\mathrm{CMT}$ treatment transiently decreased intracellular $\mathrm{A} \beta_{42} / \mathrm{A} \beta_{42}$-os levels by $24 \mathrm{~h}$ (Fig. $1 \mathrm{c}$ ). Moreover, the addition of NPS 2143 along with $\mathrm{fA} \beta_{25-35}+\mathrm{CMT}$ elicited a progressive decline in intracellular $\mathrm{A} \beta_{42} /$ $\mathrm{A} \beta_{42}$-os levels (Fig. 1c). Thus, both CMT and NPS 2143, either alone or together, hindered the fA $\beta_{25-35}$-driven intracellular build-up of $A \beta_{42} / A \beta_{42}$-os. A previous densitometric analysis of specific immunoblot bands showed that between $0 \mathrm{~h}$ and $48 \mathrm{~h}$, the total intracellular levels of $\mathrm{A} \beta_{42} / \mathrm{A} \beta_{42}$-os more than tripled in $\mathrm{fA} \beta_{25-35}$-treated astrocytes versus untreated controls. Conversely, NPS 2143 fully suppressed this $f A \beta_{25-35}$-elicited effect at all time-points (not shown; details in Armato et al. ${ }^{22}$ ).

Intracellular and secreted $A \beta_{40}$ levels. Adding CMT \pm NPS 2143 with $\mathrm{A} \beta_{25-35}$ suppressed any surge in intracellular $\mathrm{A} \beta_{40}$ levels (data not shown). fA $\beta_{25-35}+\mathrm{CMT}$ treatment decreased $\mathrm{A} \beta_{40}$ secretion only after $72 \mathrm{~h}$. NPS $2143+\mathrm{fA} \beta_{25-35}$ steadily increased $\mathrm{A} \beta_{40}$ secretion. However, adding NPS $2143+\mathrm{fA} \beta_{25-35}+\mathrm{CMT}$ caused a transient spike in $A \beta_{40}$ secretion after $24 \mathrm{~h}$ (Fig. 1b). Therefore, the pattern of $A \beta_{40}$ secretion sharply differed from that of $A \beta_{42}$ in adult human astrocytes (cf. Fig. $1 \mathrm{a}$ and b). Previously, we observed a significant $\mathrm{fA} \beta_{25-35}$-induced intracellular build-up of $A \beta_{40}$, which peaked at $24-48 \mathrm{~h}$ and was only marginally affected by NPS 2143 treatment for $48 \mathrm{~h}$; conversely, $\mathrm{fA} \beta_{25-35}$ alone did not alter the level of $\mathrm{A} \beta_{40}$ secretion versus untreated controls (for details, see ref. 22).

Secreted $A \beta_{42} / A \beta_{40}$ ratios. In the astrocyte-conditioned growth media, $\mathrm{A} \beta_{25-35}+\mathrm{CMT}$ increased the secreted $\mathrm{A} \beta_{42} / \mathrm{A} \beta_{40}$ ratio into the cytotoxic range, similar to $\mathrm{A} \beta_{25-35}$ alone (see for details ${ }^{22}$ ) (Fig. 1e). Conversely, adding NPS 2143 maintained the secreted $A \beta_{42} / A \beta_{40}$ ratios of $f A \beta_{25-35}+$ CMT-exposed astrocytes within the non-cytotoxic range observed in the controls (Fig. 1e). Therefore, by suppressing the overrelease of endogenous $\mathrm{A} \beta 42 / \mathrm{A} \beta 42$-os in the presence of A $\beta \mathrm{s}+\mathrm{CMT}$, NPS 2143 further highlighted the potential roles of A $\bullet \bullet \mathrm{CaSR}$ signalling in $\mathrm{AD}$ development.

NPS 2143 rescues the $f A \beta_{25-35} \pm C M T$-induced block in the physiological shedding of sAPP $\alpha$. Several studies have highlighted the key physiological roles hAPP NAP plays through the shedding of neurotrophic and neuroprotective sAPP $\alpha$ via $\alpha$-secretase activity ${ }^{18,25,65}$. Therefore, we investigated how sAPP $\alpha$ shedding is altered in human astrocytes exposed to $\mathrm{fA} \beta_{25-35} \pm \mathrm{CMT} \pm \mathrm{NPS} 2143$. 
$\operatorname{sAPP} \alpha$

(b)
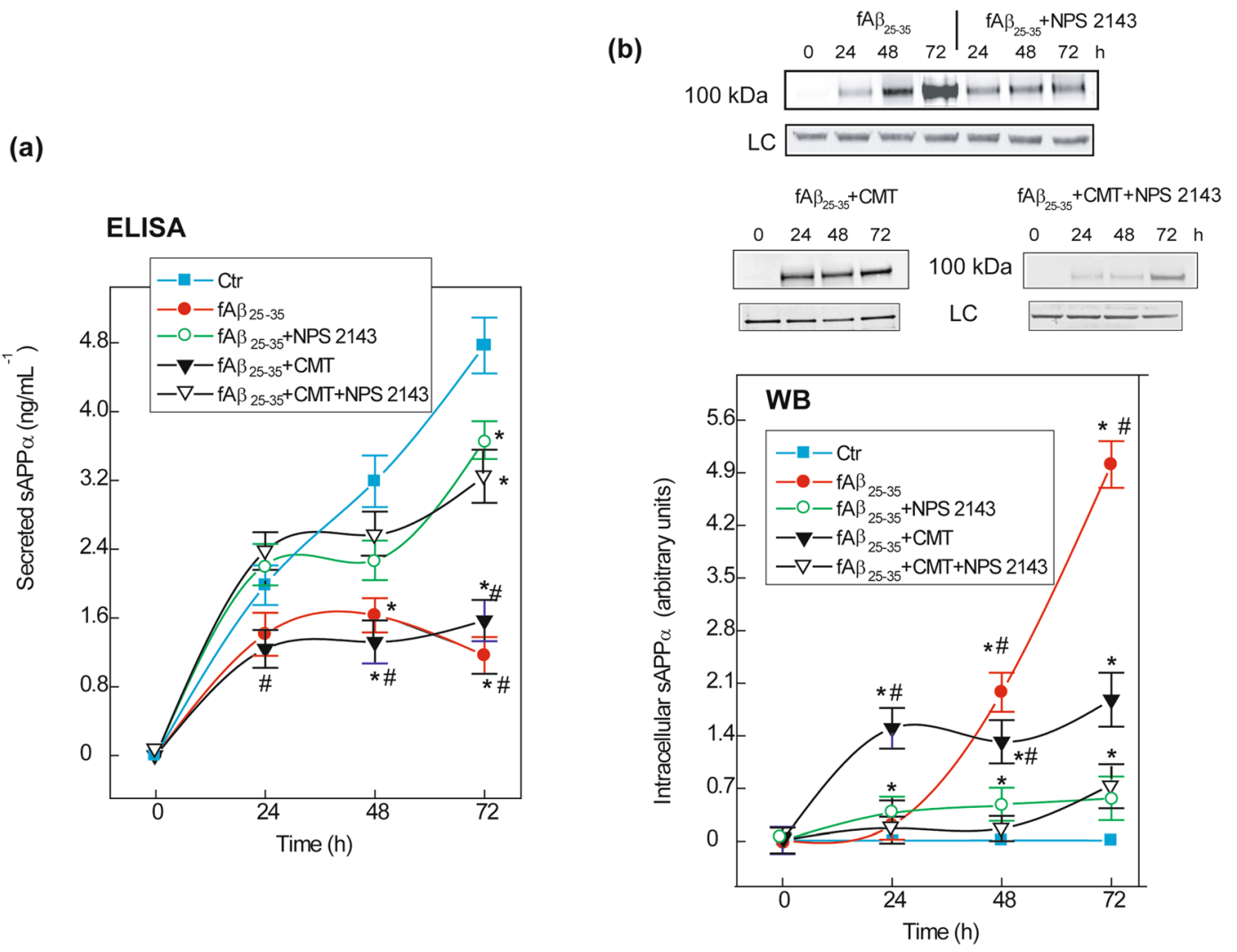

(c)

(d)
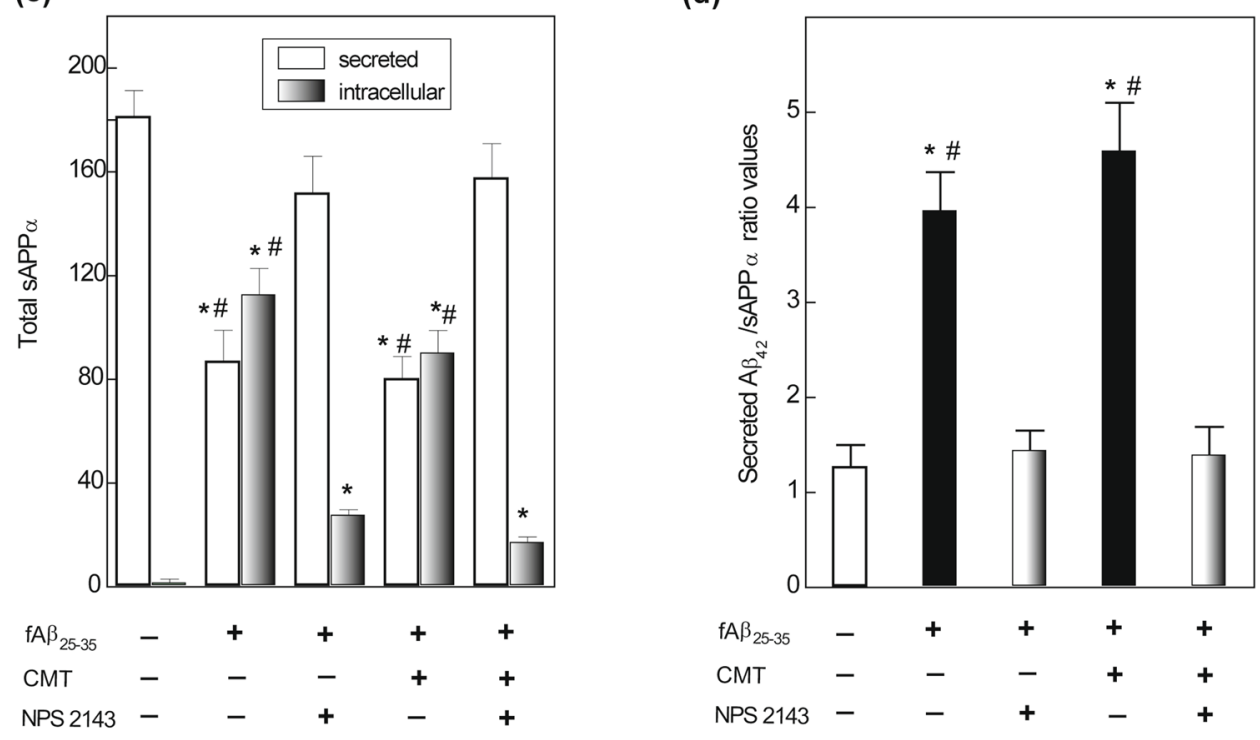

Figure 2. Changes in human astrocytes intracellularly accumulated and extracellularly shed amounts of sAPP $\alpha$ according to treatments. (a) Cumulative curves of sAPP $\alpha$ shed into the medium by astrocytes as affected by treatments. Points on the curves are means \pm SEM of 5 independent experiments. One-way ANOVA analysis of each complete data set: $\mathrm{fA} \beta_{25-35}: F=80.877, \mathrm{P}<0.001$; $\mathrm{fA} \beta_{25-35}+\mathrm{NPS} 2143: F=35.365, \mathrm{P}<0.001$; $\mathrm{fA} \beta_{25-35}+\mathrm{CMT}: F=50.882, \mathrm{P}<0.001 ; \mathrm{fA} \beta_{25-35}+\mathrm{CMT}+\mathrm{NPS} 2143: F=34.261, \mathrm{P}<0.001$. Bonferroni t-test: comparisons of each treated group versus 0 -h group (controls): $* \mathrm{P}<0.05$; pair-wise comparisons between corresponding treatments \pm NPS 2143 at each time point: ${ }^{*} \mathrm{P}<0.05$. (b) Top. Typical immunoblot revealing the changes in intracellularly accumulated SAPP $\alpha$ according to treatments versus controls $(0-\mathrm{h})$. LC, loading control. Blots have been cropped to size for clarity. Bottom. Densitometric evaluations of intracellular sAPP $\alpha$ bands. Points on the curves are means \pm SEM of 3 independent experiments, with 0 -h values normalized as 1.0. One-way ANOVA analysis of each complete data set: $\mathrm{fA} \beta_{25-35} \pm$ NPS 2143: $F=280.483, \mathrm{P}<0.001$;

$\mathrm{fA} \beta_{25-35}+\mathrm{CMT} \pm \mathrm{NPS} 2143: F=134.239, \mathrm{P}<0.001$. Bonferroni $t$-test: comparisons of each treated group versus 0 -h group (controls): $* \mathrm{P}<0.05$; pair-wise comparisons between corresponding treatments \pm NPS 
2143 at each time point: ${ }^{\#} \mathrm{P}<0.05$. (c) The alterations in total 0 -to-72-h amounts of extracellularly shed and intracellular sAPP $\alpha$ according to treatments or no treatment (controls). Bars are means \pm SEM of 3-5 independent experiments. One-way ANOVA analysis of the ( $i$ ) shed sAPP $\alpha$ complete data set: $F=44.056$, $\mathrm{P}<0.001$; (ii) intracellular sAPP $\alpha$ complete data set: $F=587.435, \mathrm{P}<0.001$. Bonferroni t-test: comparisons of each treated group versus untreated group (controls): $* \mathrm{P}<0.05$; pair-wise comparisons between corresponding treatments \pm NPS 2143 of both intracellular and shed values, respectively: ${ }^{\#} \mathrm{P}<0.05$. (d) Changes in secreted $\mathrm{A} \beta_{42} / \mathrm{sAPP} \alpha$ ratio values according to treatments or no treatment (controls). Bars are means \pm SEM of 5 separate experiments. One-way ANOVA analysis of the complete data set $F=22.123, \mathrm{P}<0.001$. Bonferroni $t$-test: comparisons of each treated group versus 0 -h (controls): $* \mathrm{P}<0.05$; pair-wise comparisons between corresponding treated group versus added NPS 2143 group: ${ }^{\#} \mathrm{P}<0.05$.

Extracellular and intracellular sAPP $\alpha$ levels. Untreated (control) astrocytes constitutively shed steady amounts of sAPP $\alpha$ into the medium (Fig. 2a). However, $\mathrm{fA} \beta_{25-35} \pm \mathrm{CMT}$ steadily and similarly decreased sAPP $\alpha$ shedding, while simultaneously inducing the oversecretion of endogenous $A \beta_{42}$ (cf. Fig. 1a). Remarkably, adding NPS 2143 to $\mathrm{fA} \beta_{25-35} \pm$ CMT rescued most of the sAPP $\alpha$ shedding (Fig. 2a).

The cleavage of hAPP by ADAM10 is reported to occur at the plasma membrane, the TGN, and in post-TGN vesicles ${ }^{27}$. Hence, we also investigated the intracellular accumulation/retention of sAPP $\alpha$ (Fig. 2b). Between $0 \mathrm{~h}$ and $72 \mathrm{~h}$, intracellular sAPP $\alpha$ was undetectable in untreated (control) astrocytes. Conversely, $\mathrm{fA} \beta_{25-35}$ alone induced a delayed but progressive increase in intra-astrocyte sAPP $\alpha$ accumulation, which was mostly abolished by NPS 2143. $\mathrm{fA}_{25-35}+$ CMT treatment also increased intra-astrocyte sAPP $\alpha$ accumulation, which was almost completely abolished by NPS 2143. Despite the ongoing increased extracellular shedding of sAPP $\alpha$ (cf. Fig. 2a), modest intracellular sAPP $\alpha$ accumulation was observed by $72 \mathrm{~h}\left(1 / 16\right.$ of that evoked by $\mathrm{fA} \beta_{25-35}$ alone) due to an unknown, A $\beta$.CaSR signalling-independent mechanism (Fig. 2b).

Total changes in SAPP $\alpha$ levels over $72 \mathrm{~h}$. A summary of the total changes in extracellularly shed (white bars) and intracellularly accumulated (black-grey bars) sAPP $\alpha$ levels over $72 \mathrm{~h}$ (derived from the areas under the respective curves) is shown in Fig. 2c. Unquestionably, $\mathrm{fA} \beta_{25-35} \pm \mathrm{CMT}$ strongly increased intracellular sAPP $\alpha$ retention while reducing its extracellular shedding (Fig. $2 a$ ) and increased the secretion of $A \beta_{42} / A \beta_{42}$-os (Fig. 1a). The $A \beta_{42} /$ sAPP $\alpha$ ratio increased between 3.9- and 4.5-fold versus the control in fA $\beta_{25-35} \pm$ CMT-treated astrocyte media, indicating a robust enhancement of hAPP AP (Fig. 2d). Conversely, adding NPS 2143 to fA $\beta_{25-35} \pm$ CMT-treated astrocytes maintained the $A \beta_{42} / s A P P \alpha$ ratio close to control levels (Fig. 2d). Clearly, by antagonizing A $\beta$.CaSR signalling, the calcilytic nearly fully restored the physiological, non-amyloidogenic shedding of neurotrophic sAPP $\alpha$ while hindering any $A \beta_{42} / A \beta_{42}$-os oversecretion from $\mathrm{fA} \beta_{25-35} \pm$ CMT-treated astrocytes (Figs $2 \mathrm{a}$ and $1 \mathrm{a}$ ).

NPS 2143 drives plasma membrane translocation of hAPP in $\mathrm{fA} \boldsymbol{\beta}_{25-35} \pm \mathrm{CMT}$-exposed astrocytes. hAPP was discretely expressed in total protein lysates of untreated astrocytes (Fig. 3a). Steady-state hAPP levels, resulting from ongoing producing and processing activities, did not change following treatment with $\mathrm{fA} \beta_{25-35}$ alone or with $\mathrm{fA} \beta_{25-35}+$ NPS 2143 (Fig. 3a). Conversely, hAPP levels increased following exposure to $\mathrm{fA} \beta_{25-35}+\mathrm{CMT}$ versus $\mathrm{fA} \beta_{25-35}$ alone, an effect that was amplified rather than counteracted by NPS 2143 (Fig. 3a).

Recent evidence indicates that promoting the delivery of hAPP to the plasma membrane or inhibiting the internalization of hAPP favours hAPP NAP ${ }^{66}$. Hence, we investigated the distribution of hAPP in cortical adult human astrocytes following $\mathrm{fA} \beta_{25-35} \pm \mathrm{CMT} \pm$ NPS 2143 -treatment. We biotinylated proteins on the astrocyte cell surface and then assessed the amount of biotinylated hAPP at the plasma membrane, with the remaining non-biotinylated hAPP regarded as "intracellular" hAPP (see Methods for details).

Plasma membrane (i.e., biotinylated) hAPP levels ( $i$ ) peaked at $48 \mathrm{~h}$ with $\mathrm{fA} \beta_{25-35}$ alone; (ii) increased from $24 \mathrm{~h}$ to $72 \mathrm{~h}$ with NPS $2143+\mathrm{fA} \beta_{25-35}$; (iii) did not change versus the controls with fA $\beta_{25-35}+\mathrm{CMT}$; and (iv) increased strongly and progressively with NPS $2143+\mathrm{fA} \beta_{25-35}+\mathrm{CMT}$ (Fig. $3 \mathrm{~b}$ ).

Simultaneously, intracellular hAPP levels $(i)$ decreased steadily and similarly with fA $\beta_{25-35} \pm$ NPS 2143 ; (ii) surged rapidly up to $24 \mathrm{~h}$ and then plateaued with $\mathrm{fA} \beta_{25-35}+\mathrm{CMT}$; and (iii) after a 24 -h delay, peaked at $48 \mathrm{~h}$ with NPS $2143+\mathrm{fA} \beta_{25-35}+\mathrm{CMT}$ and then began to decrease (Fig. 3c).

Thus, antagonizing $\mathrm{A} \beta \bullet \mathrm{CaSR}$ signalling intensified hAPP trafficking to the plasma membrane, an effect that was remarkably intensified by CMT.

NPS 2143 drives the plasma membrane translocation of ADAM10 in astrocytes, reversing the sharp decline induced by $\mathbf{f A} \boldsymbol{\beta}_{25-35} \pm \mathrm{CMT}$ treatment. ADAM10 is the key $\alpha$-secretase in hAPP physiological NAP ${ }^{19,25}$. (Concerning the effects of the various treatments on ADAM17 $\alpha$-secretase, see Fig. S2 in the Supplementary Information). Therefore, we assessed plasma membrane biotinylated and non-biotinylated (intracellular) ADAM10 (55-kDa active form) via immunoblotting (Fig. 4a,b).

Plasma membrane ADAM10. During the first $48 \mathrm{~h}$, the level of plasma membrane biotinylated 55-kDa ADAM10 decreased rapidly in $\mathrm{fA} \beta_{25-35} \pm$ CMT-treated astrocytes (Fig. 4a). However, adding NPS 2143 to fA $\beta_{25-35} \pm \mathrm{CMT}$ increased plasma membrane ADAM10 levels up to $72 \mathrm{~h}$.

Intracellular ADAM10. The levels of non-biotinylated ("intracellular") 55kDa ADAM10 greatly decreased versus the controls in $\mathrm{fA} \beta_{25-35}$-treated astrocytes and decreased further when NPS 2143 was added to fA $\beta_{25-35}$ (Fig. 4b). Conversely, intracellular ADAM10 increased transiently after approximately $48 \mathrm{~h}$ in fA $\beta_{25-35}+$ CMT-exposed astrocytes, whereas NPS $2143+\mathrm{A} \beta_{25-35}+\mathrm{CMT}$ marginally reduced intracellular ADAM10 levels. 


\section{(a) Total cell lysate}
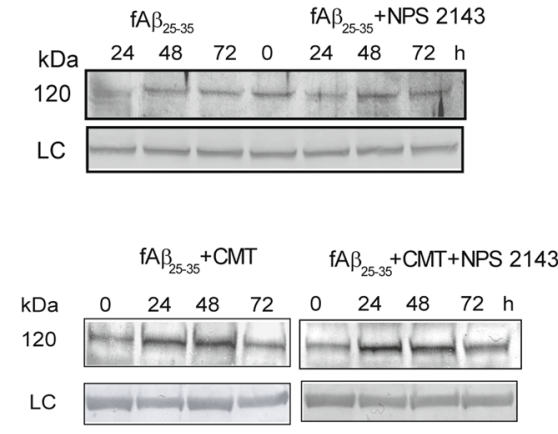

\section{(b) Plasma membrane Holo-APP}

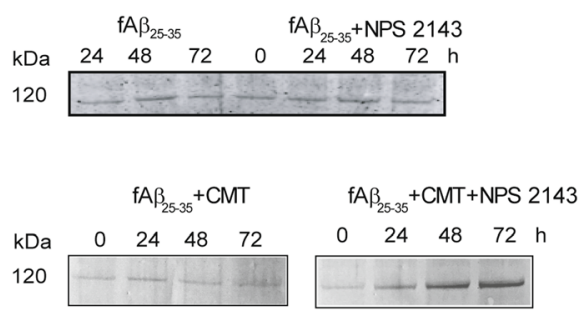

\section{(c) Intracellular Holo-APP}

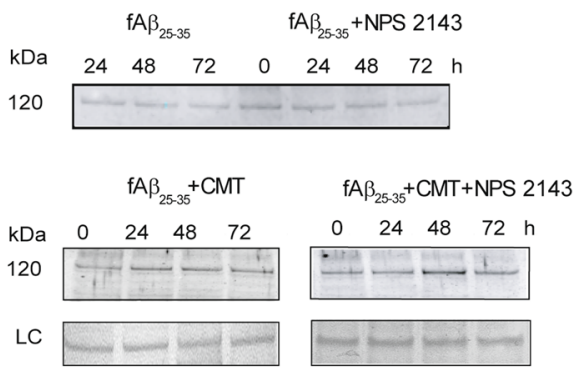

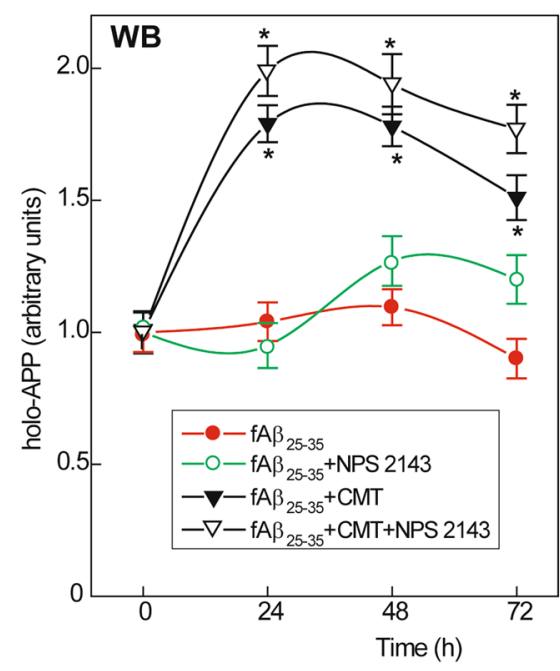
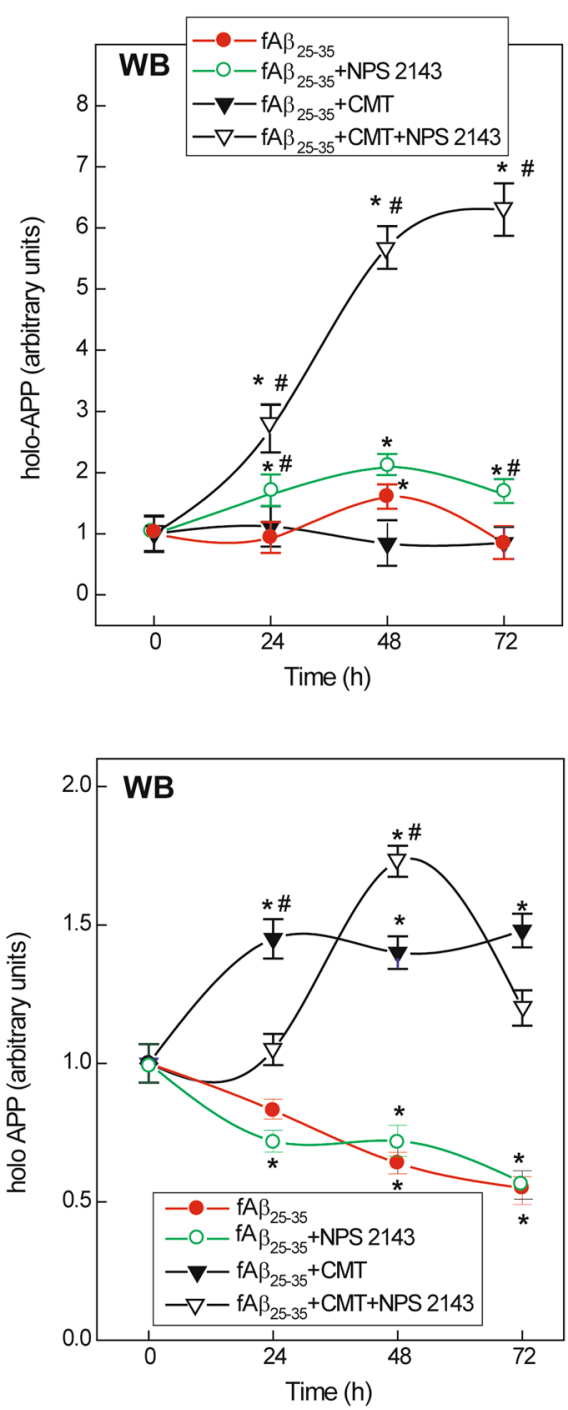

Figure 3. Holo-APP expression and distribution in human untreated and treated astrocytes. (a) Left panel. Representative immunoblots showing the changes in holo-APP expression according to experimental treatments versus untreated controls in total astrocytes lysates. LC, loading control. In all cases blots have been cropped to size for clarity. Right panel. Densitometric evaluations of holo-APP bands for each treatment and time point. Points on the curves are means \pm SEM of 3 independent experiments, with 0 -h values normalized as 1.0. One-way ANOVA analysis of the complete data set: $F=8.889, \mathrm{P}<0.001$; Bonferroni $t$-test comparisons of each treated group versus 0 -h (controls): $* \mathrm{P}<0.05$. (b) Left panel. Typical immunoblots showing alterations in plasma membrane hAPP levels (details in Methods) according to experimental treatments versus untreated 
controls. In all cases blots have been cropped to size for clarity. Right panel. Densitometric evaluation of holoAPP specific bands for each treatment and time point. Points on the curves are means \pm SEM of 3 independent experiments, with 0 -h values normalized as 1.0. One-way ANOVA analysis of ( $i$ ) fA $\beta_{25-35} \pm$ NPS 2143 data set: $F=14.520, \mathrm{P}<0.001$; $(i) \mathrm{fA} \beta_{25-35}+\mathrm{CMT} \pm \mathrm{NPS} 2143$ data set: $F=240.620, \mathrm{P}<0.001$; Bonferroni $t$-test: comparisons of each treated group versus 0 -h (controls): $* \mathrm{P}<0.05$; pair-wise comparisons between corresponding treatments \pm NPS 2143 at each time point: ${ }^{\#} \mathrm{P}<0.05$. (c) Left panel. Characteristic immunoblots showing the intracellular holo-APP's changes versus untreated $(0-\mathrm{h})$ controls according to treatments. LC, loading control. In all cases blots have been cropped to size for clarity. Right panel. Densitometric evaluations of specific holo-APP bands for each treatment and time point. Points on the curves are means \pm SEM of 3 separate experiments, with 0 -h values normalized as 1.0. One-way ANOVA analysis of: (i) fA $\beta_{25-35} \pm$ NPS 2143 data set: $F=9.800, \mathrm{P}<0.001$; (ii) $\mathrm{fA} \beta_{25-35}+\mathrm{CMT} \pm \mathrm{NPS} 2143$ data set: $F=10.710, \mathrm{P}<0.001$; Bonferroni $t$-test: comparisons of each treated group versus 0 -h (controls): $* \mathrm{P}<0.05$; pair-wise comparisons between corresponding treatments \pm NPS 2143 at each time point: ${ }^{\#} \mathrm{P}<0.05$.

NPS $2143 \pm$ CMT treatment increased the total ADAM10 specific activity in fA $\boldsymbol{\beta}_{25-35}$-exposed human astrocytes. Based on the above results, we next assessed the specific activity of ADAM10 in total protein lysates (Fig. 5a,b), which $(i)$ increased slightly with $\mathrm{fA} \beta_{25-35}$ but substantially after $24 \mathrm{~h}$ with NPS $2143+\mathrm{fA} \beta_{25-35}$; (ii) immediately increased and then remained steadily elevated with $\mathrm{fA} \beta_{25-35}+\mathrm{CMT}$ (cf. Fig. 5a); and (iii) surged rapidly with the addition of NPS 2143 to $f A \beta_{25-35}+$ CMT (Fig. 5b).

Therefore, $\mathrm{fA} \beta_{25-35}$ alone decreased both plasma membrane and intracellular ADAM10 levels. Despite the presence of $A \beta_{25-35} \pm$ CMT, NPS 2143 increased the amount of active ADAM10 at the plasma membrane, i.e., where greater hAPP translocation was also occurring (cf. Fig. 2b). These NPS 2143-driven events restored neurotrophic sAPP $\alpha$ shedding. Additionally, although it did not hinder the NPS 2143-driven plasma membrane translocation of ADAM10, CMT strongly attenuated - through an undefined mechanism - the sharp decline in intracellular ADAM10 levels elicited by fA $\beta_{25-35} \pm$ NPS 2143 .

\section{Discussion}

Currently, scant information is available about the mechanisms modulating hAPP proteolysis in cortical untransformed human neural cells. Our previous findings revealed that A $\bullet \bullet C a S R$ signalling promotes the AP of hAPP, eliciting substantial increases in endogenous $A \beta_{42}$ accumulation and secretion from adult human astrocytes and postnatal neurons ${ }^{22-24}$. Our present results show for the first time that a highly selective CaSR antagonist (calcilytic) rescues the physiological NAP of hAPP, maintaining neurotrophic and neuroprotective sAPP $\alpha$ shedding while fully suppressing pathological AP in $\mathrm{A} \beta$-exposed human astrocytes and neurons, even in the presence of microglial CMT (Fig. 6). Although our results were obtained only in astrocytes, we previously demonstrated that the effects of $A \beta \bullet C a S R$ signalling and its antagonism by a calcilytic on $A \beta_{42}$ metabolism are very similar in human neurons and astrocytes ${ }^{2-24}$. Hence, an extension of the present findings to neurons is feasible until experimentally proven. The concurrent suppression of NO overproduction and adenylate cyclase inhibition (Fig. S1) strengthens the view that NPS 2143 specifically antagonized $\mathrm{A} \beta \bullet \mathrm{CaSR}$ signalling in astrocytes.

Therefore, the present results prove for the first time that a calcilytic agent can effectively correct the balance of hAPP processing altered by A $\beta \bullet C a S R$-signalling-mediated mechanisms in cortical human astrocytes (and likely neurons) (Fig. 6). The calcilytic rescues the $\alpha$-secretase-mediated extracellular shedding of neurotrophic and neuroprotective sAPP $\alpha$ at the expense of the BACE1/ $\beta$-secretase-mediated neurotoxic $A \beta_{42}$ overrelease. The former would safeguard neuronal trophism, viability, and synaptic connections. The latter is inherently dangerous because overproduced and oversecreted soluble $A \beta_{42} / A \beta_{42}$-os and their insoluble fibrillar derivatives are endowed with a pernicious self-propagating potential. These peptides can react with CaSRs in adjacent and farther neurons and astrocytes, triggering self-spreading and self-perpetuating vicious waves of $A \beta \bullet C a S R$ signalling, and their consequent accumulation releases further $A \beta_{42} / A \beta_{42}$-os surpluses, which likely sustain LOAD progression ${ }^{22-24}$. Most remarkably, calcilytics can break such vicious cycles and hence stop $\mathrm{A} \beta_{42}$ oversecretion and intra-brain diffusion, thus safeguarding neuronal viability and function ${ }^{22-24}$. In addition, the calcilytic NPS 2143 elicits a robust downregulation of total CaSR levels in astrocytes, thereby inducing a lasting cell desensitization to exogenous $\mathrm{A} \beta \mathrm{s} \bullet \mathrm{CaSR}$-driven noxious effects ${ }^{22}$.

Regarding the mechanisms of calcilytics, NPS 2143 notably $(i)$ drives a substantial translocation of hAPP, as well as both the precursor $(85 \mathrm{kDa}$; not shown) and active $(55 \mathrm{kDa})$ forms of ADAM10 $\alpha$-secretase, to the astrocyte plasma membrane; (ii) greatly increases the total ADAM10 $\alpha$-secretase specific activity, particularly in the presence of CMT; ( iii) maintains the intracellular levels of active ADAM10 (55 kDa) at or above basal values; and (iv) restores neurotrophic and neuroprotective sAPP $\alpha$ extracellular shedding close to untreated control levels while hindering the intracellular accumulation of $\operatorname{SAPP} \alpha$. Consequently, by concomitantly also suppressing any surplus $A \beta_{42}$ release, NPS 2143 maintains the secreted $A \beta_{42} / s A P P \alpha$ and $A \beta_{42} / A \beta_{40}$ ratios near controls levels.

As with other type-I transmembrane proteins, hAPP is synthesized in the endoplasmic reticulum (ER). Then, hAPP undergoes maturation (glycosylation) while migrating to the Golgi/TGN compartment, where it is mainly found in neurons ${ }^{66}$. Finally, hAPP reaches the plasma membrane via the constitutive secretory pathway, where it is inserted to be cleaved by ADAM10 (mainly) $\alpha$-secretase, shedding the SAPP $\alpha$ ectodomain, which also occurs in a post-Golgi compartment ${ }^{67}$. In addition, through the recognition of its YENPTY motif and clathrin-coated pits, hAPP can be quickly endocytosed from the plasma membrane and trafficked back to the membrane, delivered through endosomes to the lysosomal system for proteolysis ${ }^{66}$ or alternatively cleaved by BACE $1 / \beta$-secretase, shedding $\mathrm{A} \beta$ s (the amyloidogenic pathway), particularly if retained in acidic late endosomes, the TGN or $\mathrm{ER}^{67}$. Thus, favouring the plasma membrane trafficking or retention of hAPP blocks A $\beta$ production while enhancing 


\section{$\operatorname{ADAM} 10(55 \mathrm{kDa})$}

\section{(a) Plasma membrane}
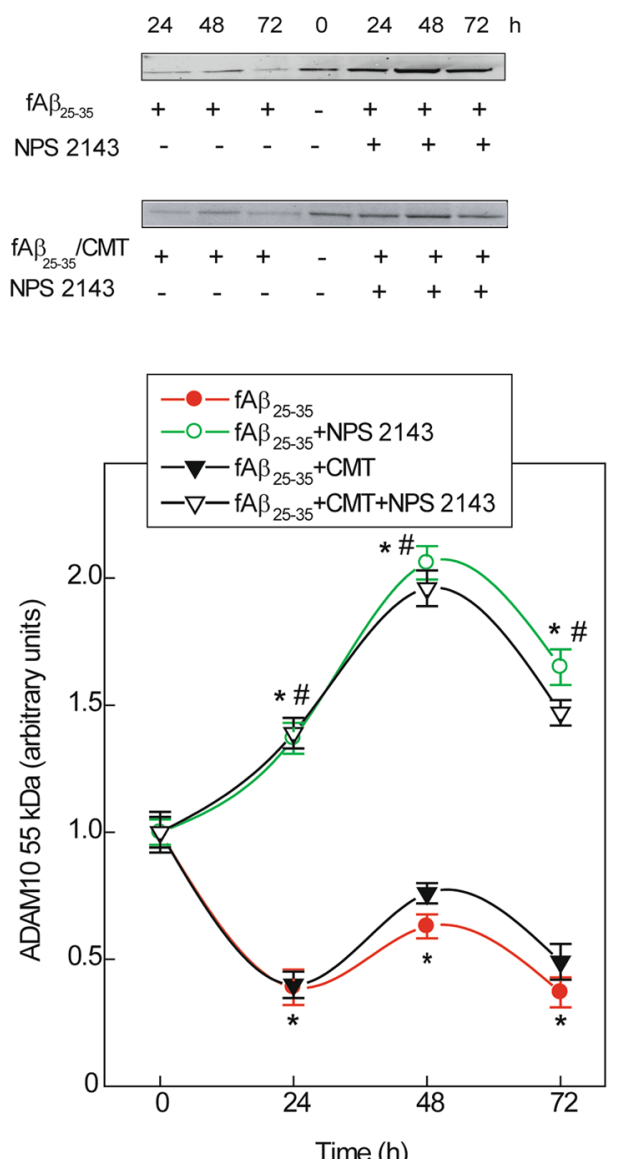

\section{(b) Intracellular}
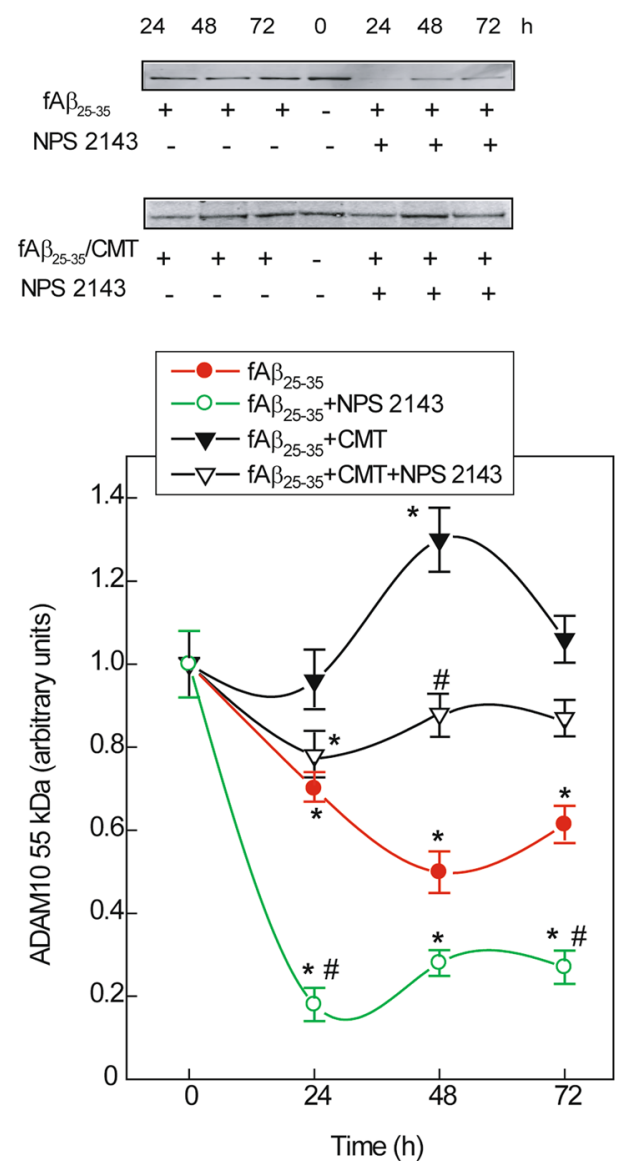

Figure 4. Changes in ADAM10 protein expression and subcellular distribution in human astrocytes. (a) Top. Typical immunoblots revealing changes in cell surface biotinylated ADAM10 levels (details in Methods) according to experimental treatments versus untreated controls. Blots have been cropped to size for clarity. Bottom. Densitometric evaluations of specific ADAM10 bands for each treatment and time point. Points in the curves are means \pm SEM of 3 independent experiments, with 0 -h (controls) values normalized as 1.0. One-way ANOVA analysis of $(i) \mathrm{fA} \beta 25-35 \pm \mathrm{NPS} 2143$ data set: $F=73.625, \mathrm{P}<0.001$; (ii) fA $\beta_{25-35}+\mathrm{CMT} \pm \mathrm{NPS} 2143$ data set: $F=55.591, \mathrm{P}<0.001$; Bonferroni $t$-test: comparisons of each treated group versus 0 -h group (controls): $* \mathrm{P}<0.05$; pair-wise comparisons between corresponding treatments $\pm \mathrm{NPS} 2143$ at each time point: ${ }^{*} \mathrm{P}<0.05$. (b) Top. Characteristic immunoblots exposing changes in the levels of non-biotinylated intracellular ADAM10 according to the specific treatments versus untreated controls. In all cases blots have been cropped to size for clarity. Bottom. Densitometric evaluation of specific ADAM10 bands for each treatment and time point. Points in the curves are means \pm SEM of 3 independent experiments, with 0 -h values normalized as 1.0. One-way ANOVA analysis of $(i) \mathrm{fA} \beta_{25-35} \pm \mathrm{NPS} 2143$ data set: $F=34.818, \mathrm{P}<0.001$; (ii) fA $\beta_{25-35}+\mathrm{CMT} \pm \mathrm{NPS} 2143$ data set: $F=10.938, \mathrm{P}<0.001$; Bonferroni t-test: comparisons of each treated group versus 0 -h (controls): $* \mathrm{P}<0.05$; pair-wise comparisons between corresponding treatments \pm NPS 2143 at each time point: ${ }^{\#} \mathrm{P}<0.05$.

sAPP $\alpha$ extracellular shedding via ADAM10 cleavage. hAPP trafficking is regulated by factors that promote A $\beta$ generation, such as the SNX family (SNX17 and SNX33), dynamin I, and the RAB GTPase family (RAB1B, RAB6, $\mathrm{RAB} 8$, and $\mathrm{RAB} 11)^{68}$. In addition, factors that regulating $\alpha-, \beta-$, and $\gamma$-secretase trafficking are able to alter hAPP processing and, hence, impact the production of sAPP $\alpha$ or $A \beta s^{68}$. Further investigations will clarify the roles played by such factors in human astrocytes.

The activation of a number of cell surface receptors, e.g., muscarinic acetylcholine receptors, platelet-derived growth factor (PDGF) receptors, serotonin/5-hydroxytryptamine $\left(5-\mathrm{HT}_{4}\right)$ receptors, and metabotropic glutamate receptors, reportedly exerts differential effects on hAPP AP or NAP ${ }^{69}$. Our findings add CaSRs to this group of receptors. These receptors activate various signalling pathways that regulate extracellular $\mathrm{A} \beta$ secretion and sAPP $\alpha$ shedding via changes in cytosolic $\left[\mathrm{Ca}^{2+}\right]_{\mathrm{i}}, \mathrm{cAMP}$, inositol 1,4,5-triphosphate, small Rac GTPases, and in the activity of a number of protein kinases, including PKA, PKC, mitogen activated protein kinase kinase 


\section{ADAM 10 Specific Enzymatic Activity}

(a)

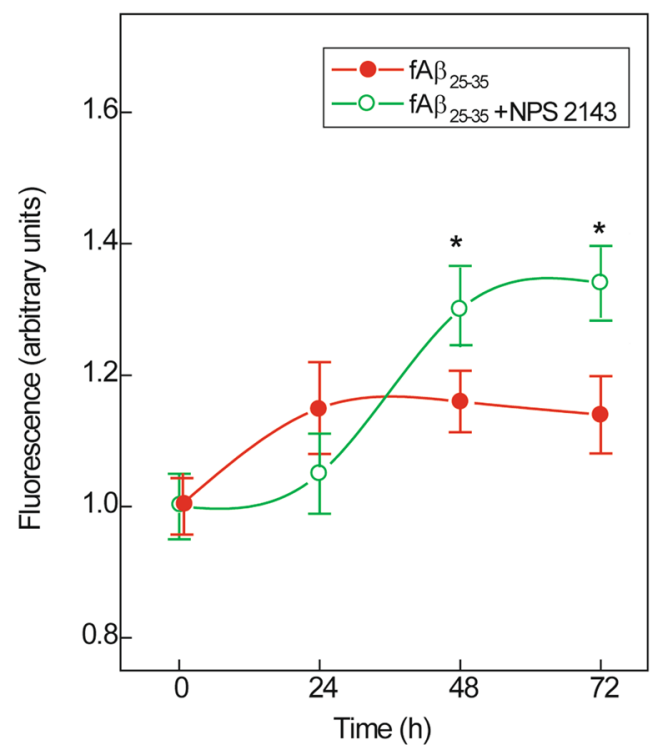

(b)

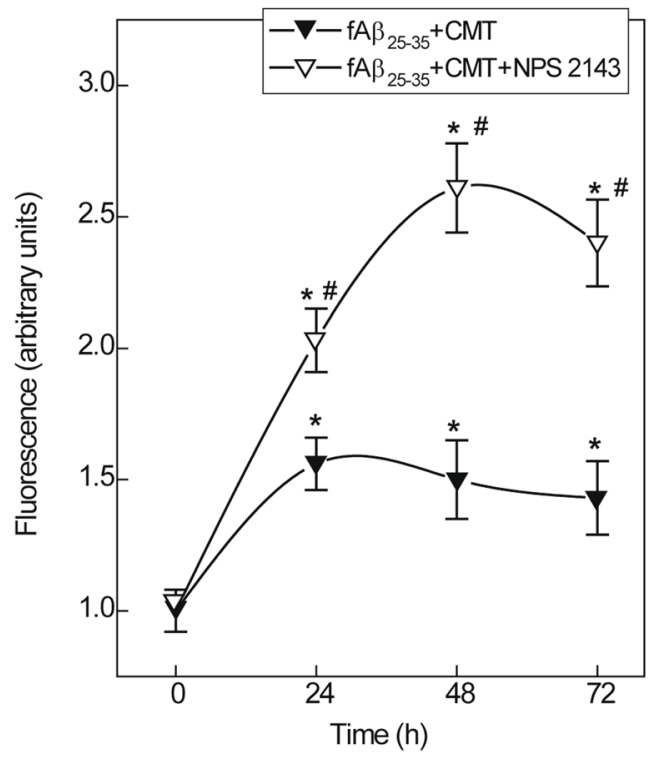

Figure 5. ADAM10 specific enzymatic activity alterations in human astrocyte protein lysates. (a) Changes in ADAM10 specific activity after an exposure to $f A \beta_{25-35} \pm$ NPS 2143. (b) Alterations in ADAM10 specific activity increases after treatment with $\mathrm{fA} \beta_{25-35}+\mathrm{CMT} \pm$ NPS 2143 . The specific activities in $\mathbf{A}$ and $\mathbf{B}$ were assayed as described in the Methods section. Points on the curves are means \pm SEM of 3 independent experiments with 0 -h values normalized as 1.0. One-way ANOVA analysis of: (i) $\mathrm{fA} \beta_{25-35} \pm \mathrm{NPS} 2143$ data set: $F=7.923, \mathrm{P}<0.001$; (ii) $\mathrm{fA} \beta_{25-35}+\mathrm{CMT} \pm \mathrm{NPS} 2143$ data set: $F=74.248, \mathrm{P}<0.001$; Bonferroni $t$-test: comparisons of each treated group versus 0 -h (controls): $* \mathrm{P}<0.05$; pair-wise comparisons of corresponding treatments \pm NPS 2143 at each time point: ${ }^{\#} \mathrm{P}<0.05$.

(MAPKK), extracellular signal-regulated kinase (ERK), phosphatidylinositol-3-kinase (PI3K), and Src tyrosine kinase $^{69}$. Reduced cholesterol levels also heighten ADAM10 activity and hinder hAPP endocytosis, thus enhancing sAPP $\alpha$ shedding from cultured cells ${ }^{69}$. Similar effects can be obtained via ADAM10 overexpression ${ }^{70}$, pharmacological muscarinic activation ${ }^{32}$ or phorbol myristate acetate treatment in hAPP-transfected CHO cells ${ }^{27}$. Conversely, the AP of hAPP was favoured at the expense of sAPP $\alpha$ extracellular shedding following overexpression of BACE1/ $\beta$-secretase ${ }^{40}$ or the Swedish mutant form of hAPP (SweAPP), which is linked to a familial EOFAD and is more effectively cleaved by BACE $1 / \beta$-secretase within the $\mathrm{TGN}^{69}$. In addition, knocking down ADAM $10^{25}$ and expressing a dominant-negative ADAM10 mutant in mice ${ }^{70}$ both increased hAPP AP.

ADAM family members belong to the metzincin superfamily and are typically synthesized as inactive precursors (zymogens) ${ }^{71}$. The proteolytic removal of a conserved cysteine switch in the prodomain is necessary to activate these zymogens ${ }^{71}$. Our findings indicate that cleavage by proprotein convertases (e.g., furin and PC7 in HEK293 cells ${ }^{72}$ ) into the $55-\mathrm{kDa}$ ADAM10 active form occurs at the cell surface of human astrocytes rather than in late compartments of the secretory pathway. However, the complex mechanisms modulating $\alpha$-secretase cleavage activity are not fully elucidated. ADAM10 is not the sole constitutive $\alpha$-secretase in neurons ${ }^{25,73}$. The present findings indicate that antagonizing A $\beta$.CaSR signalling with a calcilytic agent, in the absence but more effectively in the presence of CMT, increases the regulated ADAM10 $\alpha$-secretase specific activity in adult human astrocytes. Treatment with NPS 2143 drives the plasma membrane translocation of both ADAM10 and hAPP in $\mathrm{fA} \beta_{25-35}+\mathrm{CMT}$-exposed astrocytes. This finding reveals that $\mathrm{A} \beta \cdot \mathrm{CaSR}$ signalling alone restrains the vesicular transport of hAPP and ADAM10 to the plasma membrane, while raising hAPP intracellular levels and AP.

Although it increased ADAM10 $\alpha$-secretase specific activity, CMT addition had little to no impact on daily and cumulative (i.e., over $72 \mathrm{~h}$ ) extracellular sAPP $\alpha$ secretion. Only NPS 2143 addition restored sAPP $\alpha$ secretion to the levels of untreated astrocytes, showing the importance of blocking A $\beta \bullet C a S R$ signalling is in restoring hAPP NAP. Regarding the intracellular storage of $\mathrm{sAPP} \alpha$, which did not occur in the untreated astrocytes, CMT addition altered the kinetics but not the total amount stored in $\mathrm{fA} \beta_{25-35}$-exposed astrocytes. As expected, NPS 2143 reduced most but not all) of the sAPP $\alpha$ storage caused by $f A \beta_{25-35}$ treatment, even in the presence of CMT. The reasons why these minor SAPP $\alpha$ fractions were retained regardless of NPS 2143 and CMT treatment are not currently understood. Intracellular SAPP $\alpha$ accumulation has also been observed in other cellular models, including cultured human thyroid cells ${ }^{50}$.

Increased cleavage of hAPP by $\alpha$-secretase was previously suggested as a therapeutic approach to $\mathrm{AD}^{32}$. Our present results strengthen the role of calcilytics as prospective drugs for AD therapy (Fig. 6). In this regard, calcilytics benefits largely overcome the mild hyperparathyroidism they induce in humans, given that AD "inexorably 

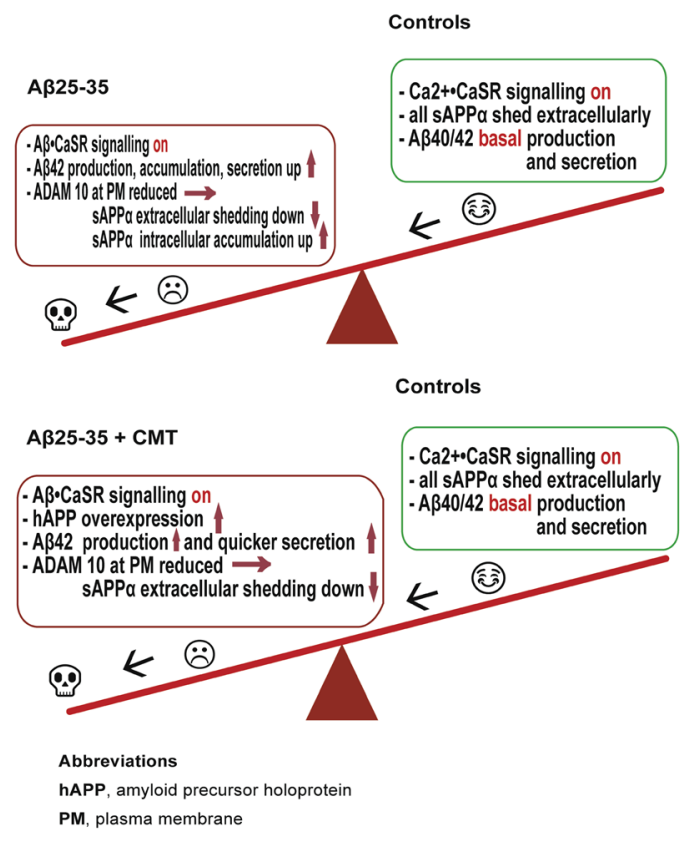

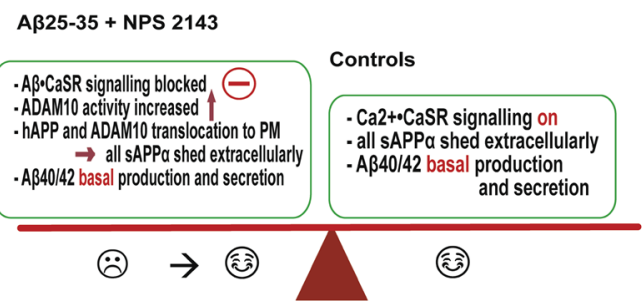

$A \beta 25-35+C M T+N P S 2143$

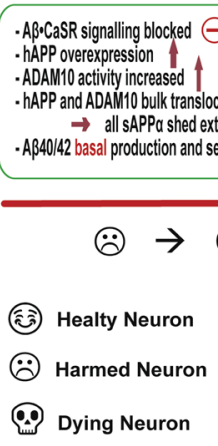

Figure 6. Mechanisms synopsis. Cartoon illustrating the concept that CaSR-dependent signalling can deeply affect the balance between hAPP NAP and AP and hence play a role in the promotion or prevention of AD development. Left panel. The main mechanisms by which $\mathrm{A} \beta_{25-35}$ alone (top) or $+\mathrm{CMT}$ (bottom) alters the hAPP physiological NAP in favour of AP. Right panel. The main mechanisms by which calcilytic NPS 2143 restores the hAPP NAP while hindering the AP in $\mathrm{A} \beta_{25-35}$-exposed adult human astrocytes either in absence (top) or in the presence of CMT (bottom). The emojis indicate what most likely happens to the neurons exposed to the various agents (human astrocytes survive). See the text for further details.

kills the patient cognitively several years before his/her actual physical demise"22-24. Therefore, the negative consequences of calcilytics should prove negligible if clinical trials prove that they can halt $\mathrm{AD}$ development.

\section{Methods}

Cell cultures. Untransformed human adult astrocytes were isolated from anonymized surgical fragments of normal adult human temporal cortex (brain trauma leftovers) provided by several Neurosurgery Units after obtaining written informed consent from all the patients and/or their next-of-kin. Experimental use of isolated astrocytes was approved by the Ethical Committee of Verona University-Hospital Integrated Company. All human cells experiments were performed in accordance with the relevant guidelines and regulations of Verona University-Hospital Integrated Company. Cultures of astrocytes were set up, as previously described ${ }^{22}$, in a medium consisting of $89 \%(\mathrm{v} / \mathrm{v})$ of a 1:1 mixture of DMEM and F-12 medium (Life Technologies Italia, Monza, Italy), $10 \%\left(\mathrm{v} / \mathrm{v}\right.$ ) heat-inactivated (at $56^{\circ} \mathrm{C}$ for $30 \mathrm{~min}$ ) foetal bovine serum (FBS; Life Technologies Italia) and $1 \%$ $(\mathrm{v} / \mathrm{v})$ of a penicillin-streptomycin solution (Lonza Milano, Italy). When the primary cultures reached $70 \%$ confluence (4 weeks), the cells were detached with $0.25 \%$ (w/v) trypsin and $0.02 \%(w / v)$ EDTA (Lonza) in Hanks BSS, split 1:4 and planted in new flasks. After the third subculture a homogeneous population of astrocytes obtained. In these pure cultures, the cells only expressed astrocyte-specific markers such as glial fibrillary acid protein (GFAP) and glutamine synthase (GS). None of the cells expressed neuronal (enolase), oligodendrocytes (galactocerebroside), microglia (CD-68), or endothelial cells (factor VIII) markers. These astrocytes proliferated quite slowly in serum-enriched DMEM (Life Technologies Italia) medium and were by now phenotypically "locked-in".

A $\beta$ peptides. $A \beta_{25-35}$ (Bachem), a known $A \beta_{1-42}$ proxy ${ }^{22}$, was dissolved at $1.5 \mathrm{mM}$ in PBS. Fibrillogenesis by $\mathrm{A} \beta_{25-35}$ was checked via thioflavin-T tests before experimental use. The reversemer peptide $\mathrm{A} \beta_{35-25}$ (Bachem) was dissolved in the same way as $A \beta_{25-35}$, but did not form fibrils and when given to the cultures was totally ineffective (not shown).

Experimental protocol. Since astrocytes do not actively divide in the adult human brain, we employed them once they had reached mitotic quiescence. At experimental " 0 h", culture flasks served partly as untreated controls receiving a change of fresh medium and partly received fresh medium with $20 \mu \mathrm{M}$ of either fibrillar (f) $\mathrm{A} \beta_{25-35}$ or reversemer $A \beta_{35-25}$ added. This dose of the fA $\beta$ s had been found to be ideal in previous studies ${ }^{22-24}$. Part of the treated cultures received $20 \mu \mathrm{M}$ of $\mathrm{fA} \beta_{25-35}$ once (at $0 \mathrm{~h}$ ) plus a cytokine mixture trio (CMT), that is IL-1 $\beta\left(20 \mathrm{ng} \mathrm{mL}^{-1}\right)$, TNF- $\alpha\left(20 \mathrm{ng} \mathrm{mL}^{-1}\right)$, and IFN- $\gamma\left(70 \mathrm{ng} \mathrm{mL}^{-1}\right)$ (all from PeproTech, London, England). A 
second and a third CMT bolus was added at 24-h and 48-h. The CaSR allosteric antagonist (calcilytic) NPS 2143 $\mathrm{HCl}$ (2-chloro-6-[(2 R)-3-1,1-dimethyl-2-(2-naphtyl) -ethylamino-2-hydroxy-propoxy]-benzonitrile $\mathrm{HCl}$; Tocris Bioscience, $\mathrm{UK})^{54}$ was dissolved in DMSO and next diluted in the growth medium at a final concentration of $100 \mathrm{nM}$. At experimental " $0-h$ ", "24-h", and " $48-h$ " part of the astrocyte cultures were exposed for 30 min to NPS 2143 dissolved in fresh medium. Next, the NPS 2143-containing medium was removed and fresh (at 0.5-h) medium or the previously astrocyte-conditioned (at 24.5 and $48.5-\mathrm{h}$ ) media were added again to the cultures. Cultures and cell-conditioned media were sampled at 24 hourly intervals. Phosphoramidon (10 $\mu \mathrm{M}$; Sigma), an inhibitor of thermolysin and other proteases, was added to the media at " 0 -h" experimental time.

Western immunoblotting (WB). At selected time points, control and treated astrocytes were scraped into cold PBS, sedimented at $200 \times g$ for $10 \mathrm{~min}$, and homogenized in T-PER ${ }^{\mathrm{TM}}$ tissue protein extraction reagent (Thermo Scientific, Rockford, USA) containing complete EDTA-free protease inhibitor cocktail (Roche, Milan). Equal amounts $(10-30 \mu \mathrm{g})$ of protein from the samples were loaded on NuPAGE Novex 4-12\% Bis-Tris polyacrylamide gel (Life Technologies Italia) and next blotted onto nitrocellulose membranes $(0.2 \mu \mathrm{m})$ by means of iBlot $^{\mathrm{TM}}$ Dry Blotting System (Life Technologies Italia). The membranes were probed with: $(i)$ rabbit polyclonal anti-Amyloid Precursor Protein (APP), C-Terminal (751-770) diluted 1:2000 (Calbiochem; Merck, Darmastadt, Germany); (ii) mouse monoclonal 2B3 antibody anti-sAPP $\alpha$ human C-terminal peptide (IBL International $\mathrm{GmbH}$, Hamburg, Germany), diluted at $2.0 \mu \mathrm{g} \mathrm{mL} \mathrm{L}^{-1}$; (iii) mouse monoclonal antibody anti-ADAM10 (A3, Santa Cruz Biotechnology, Germany) used at $1.0 \mu \mathrm{g} \mathrm{mL}^{-1}$; (iv) mouse monoclonal antibody anti-A $\beta_{42}$ (8G7, Acris Antibodies $\mathrm{GmbH}$, Germany) used at $1.0 \mu \mathrm{g} \mathrm{mL}^{-1}$; and $(v)$ goat polyclonal antibody anti-lamin B (Santa Cruz Biotechnology) which served to assess loading controls used at $1.0 \mu \mathrm{g} \mathrm{mL}^{-1}$. The integrated intensities of the bands specific for each protein of interest were assessed using the Sigmagel ${ }^{\mathrm{TM}}$ software package (Jandel Corp., Erkrath, Germany).

Biotinylation and isolation of astrocytes' plasmalemmal proteins. The Pierce ${ }^{\mathrm{TM}}$ Cell Surface Protein Isolation Kit (Thermo Scientific) served to biotinylate and isolate cell surface proteins. According to the supplier's procedure the cell culture media were removed and astrocytes were washed twice with ice-cold PBS followed by incubation with $0.25 \mathrm{mg} \mathrm{mL}^{-1}$ Sulfo-NHS-SS-Biotin in ice-cold PBS on a rocking platform for 30 minutes at $4{ }^{\circ} \mathrm{C}$. The biotinylation reaction was quenched by adding $500 \mu \mathrm{l}$ of the provided Quenching Solution (Pierce). Astrocytes were harvested by gentle scraping and pelleted by centrifugation at $500 \times g$ for 5 minutes at $4{ }^{\circ} \mathrm{C}$. After washing with TBS astrocyte pellets were lysed using the provided Lysis Buffer (Pierce) containing a protease inhibitor cocktail (Roche) for 30 minutes on ice with intermittent vortexing. To get rid of cell remnants, the lysates were centrifuged at $10,000 \times g$ for 2 minutes at $4{ }^{\circ} \mathrm{C}$. To purify biotinylated proteins on Immobilized NeutrAvidin Gel, the clarified supernatant was incubated for 1-h at room temperature (RT) to allow the biotinylated proteins to bind to the NeutrAvidin Gel. The unbound proteins, representing the intracellular fraction, were collected by centrifugation of the column at $1,000 \times g$ for 2 minutes. Any remaining unbound proteins were removed by washing thrice with Wash Buffer (Pierce). Finally, the biotinylated surface proteins were eluted from the biotin-NeutrAvidin Gel by incubation with $400 \mu \mathrm{L}$ of the SDS-PAGE Sample Buffer containing $50 \mathrm{nM}$ DTT for 1 -h at RT in the end-over-end tumbler, and were collected by column centrifugation at $1,000 \times g$ for 2 minutes.

Assays of $\alpha$-secretases specific activities. The ADAM10 and ADAM17 enzymatic activities were assayed by means of fluorescent methods using EnSens ${ }^{\mathrm{TM}}$ ADAM10 and EnSens ${ }^{\mathrm{TM}}$ ADAM17 activity detection kits (Enzium, Inc., Philadelphia, USA) in the cell lysates. Despite the highly-overlapping substrate specificities of ADAM10 and ADAM17, EnSens ${ }^{\mathrm{TM}}$ substrates are able to differentiate between the two enzymes. Astrocytes' lysates $(20 \mu \mathrm{g})$ were incubated with the fluorogenic EnSens ${ }^{\mathrm{TM}}$ ADAM10 and EnSens ${ }^{\mathrm{TM}}$ ADAM17 substrates, respectively for 1-h at RT, protected from light according to the supplier's protocol. The fluorescence was recorded at excitation and emission wavelengths of $625-635 \mathrm{~nm}$ and $655-665 \mathrm{~nm}$, respectively. The results were expressed as specific activity (means \pm SEMs of $\Delta \mathrm{F}_{\mu \mathrm{g}}^{-1}$ protein pertaining to each experimental group).

Enzyme-linked immunoassays (ELISAs) of $A \beta_{42}, A \beta_{40}$, and SAPP $\alpha$ released into in cell-conditioned growth media. Quantifications of $A \beta_{42}$, and $A \beta_{40}$ and sAPP $\alpha$ were carried out by means of specific $A \beta_{42}$, and $A \beta_{40}$ Human/Rat High-Sensitive ELISA Kits (both from Wako, Japan) as previously described $^{22}$ and by means of specific Human sAPP $\alpha$ High-Sensitive ELISA Kit (from IBL International). Briefly, the astrocytes conditioned media samples were added with a protease inhibitor cocktail (Roche) and centrifuged for 10 minutes at 13,000 rpm to remove any cellular debris. Supernatants were tested in triplicate according to the manufacturer protocol.

Statistical analysis. The data were analyzed using Sigma Stat $3.5^{\mathrm{TM}}$ Advisory Statistics for Scientists (Systat Software). For immunoblotting, bands' densitometric data were normalized to matching loading control (lamin B1) bands and next analyzed by one-way ANOVA. When the ANOVA's upshot was significant $(\mathrm{P}<0.05)$, Bonferroni $t$-test, was used for all pairwise comparisons and multiple comparisons versus 0 - $h$ (untreated) control values. Null hypotheses were rejected when $\mathrm{P}>0.05$.

\section{References}

1. Alzheimer's Association. 2012 Alzheimer's disease facts and figures. Alzheimer's Dement 8, 131-168, doi:10.1016/j.jalz.2012.02.001 (2012).

2. Braak, H. \& Braak, E. Neuropathological staging of Alzheimer-related changes. Acta Neuropathol 82, 239-259, doi:10.1007/ BF00308809 (1991).

3. Masters, C. L. \& Selkoe, D. J. Biochemistry of amyloid- $\beta$ protein and amyloid deposits in Alzheimer disease, in: The Biology of Alzheimer's Disease, (Eds Selkoe, D. J., Mandelkow, E. D. \& Holzman, M.) 181-204 (Cold Spring Harbor Laboratory Press 2012). 
4. Mawuenyega, K. G. et al. Decreased clearance of CNS beta-amyloid in Alzheimer's disease. Science 330, 1774-1774, doi:10.1126/ science.1197623 (2010).

5. Armstrong, R. A. Spatial patterns of $\beta$-amyloid (A $\beta)$ deposits in familial and sporadic Alzheimer's disease. Folia Neuropathol 49, 153-161 (2011)

6. Benzinger, T. L. et al. Regional variability of imaging biomarkers in autosomal dominant Alzheimer's disease. Proc Natl Acad Sci USA 110, E4502-4509, doi:10.1073/pnas.1317918110 (2013).

7. Müller, U. C. \& Zheng, H. Physiological functions of APP family proteins. Cold Spring Harb Perspect Med 2, a006288-a006288, doi:10.1101/cshperspect.a006288 (2012).

8. Zheng, H. \& Koo, E. Biology and pathophysiology of the amyloid precursor protein. Mol Neurodegener 6, 27, doi:10.1186/17501326-6-27 (2011).

9. Deyts, C., Thinakaran, G. \& Parent, A. T. APP receptor? To be or not to be. Trends Pharm Sc 37, 390-411, doi:10.1016/j. tips.2016.01.005 (2016).

10. Milosch, N. et al. Holo-APP and G-protein-mediated signaling are required for sAPP $\alpha$-induced activation of the Akt survival pathway. Cell Death Dis 5, e1391, doi:10.1038/cddis.2014.352 (2014).

11. Koo, E. H. \& Squazzo, S. L. Evidence that production and release of amyloid-beta protein involves the endocytic pathway. J Biol Chem 269, 17386-17389 (1994).

12. Tienari, P. J. et al. Intracellular and secreted Alzheimer $\beta$-amyloid species are generated by distinct mechanisms in cultured hippocampal neurons. Proc Natl Acad Sci USA 94, 4125-4130 (1997).

13. Huse, J. T. \& Doms, R. W. Neurotoxic traffic. Uncovering the mechanics of amyloid production in Alzheimer disease. Traffic 2, 75-81, doi:10.1034/j.1600-0854.2001.020201.x (2001).

14. Rossner, S., Sastre, M., Bourne, K. \& Lichtenthaler, S. F. Transcriptional and translational regulation of BACE1 expression-implications for Alzheimer's disease. Prog Neurobiol 79, 95-111, doi:10.1016/j.pneurobio.2006.06.001 (2006).

15. Cole, S. L. \& Vassar, R. The role of amyloid precursor protein processing by BACE1, the beta-secretase, in Alzheimer disease pathophysiology. J Biol Chem 283, 29621-29625, doi:10.1074/jbc.R800015200 (2008).

16. Cao, X. \& Sudhof, T. C. Dissection of amyloid-beta precursor protein-dependent transcriptional transactivation. J Biol Chem 279, 24601-24611, doi:10.1074/jbc.M402248200 (2004)

17. Hebert, S. S. et al. Regulated intramembrane proteolysis of amyloid precursor protein and regulation of expression of putative target genes. EMBO Rep 7, 739-745, doi:10.1038/sj.embor.7400704 (2006).

18. Prox, J., Rittger, A. \& Saftig, P. Physiological functions of the amyloid precursor protein secretases ADAM10, BACE1, and presenilin. Exp Brain Res 217, 331-341, doi:10.1007/s00221-011-2952-0 (2012).

19. Selkoe, D. J. Alzheimer's disease. Cold Spring Harbor Perspect Biol 3, 7-a004457, doi:10.1101/cshperspect.a004457 (2011).

20. Ising, C., Stanley, M. \& Holtzman, D. M. Current thinking on the mechanistic basis of Alzheimer's and implications for drug development. Clin Pharmacol Ther 98, 469-471, doi:10.1002/cpt.200 (2015).

21. Domert, J. et al. Spreading of amyloid- $\beta$ peptides via neuritic cell-to-cell transfer is dependent on insufficient cellular clearance. Neurobiol Dis 65, 82-92, doi:10.1016/j.nbd.2013.12.019 (2014).

22. Armato, U. et al. Calcium-sensing receptor antagonist (calcilytic) NPS 2143 specifically blocks the increased secretion of endogenous A $\beta 42$ prompted by exogenous fibrillary or soluble $A \beta 25-35$ in human cortical astrocytes and neurons-Therapeutic relevance to Alzheimer's disease. Biochim Biophys Acta-Mol Basis Dis 1832, 1634-1652, doi:10.1016/j.bbadis.2013.04.020 (2013).

23. Dal Prà, I. et al. Do astrocytes collaborate with neurons in spreading the "infectious" A $\beta$ and Tau drivers of Alzheimer's disease? Neuroscientist 21, 9-29, doi:10.1177/1073858414529828 (2015).

24. Chiarini, A., Armato, U., Liu, D. \& Dal Prà, I. Calcium-Sensing Receptors of Human Neural Cells Play Crucial Roles in Alzheimer's Disease. Front Physiol 7, 134, doi:10.3389/fphys.2016.00134 (2016).

25. Kuhn, P. H. et al. ADAM10 is the physiologically relevant, constitutive alpha-secretase of the amyloid precursor protein in primary neurons. EMBO J 29, 3020-3032, doi:10.1038/emboj.2010.167 (2010).

26. Parvathy, S., Hussain, I., Karran, E. H., Turner, A. J. \& Hooper, N. M. Cleavage of Alzheimer amyloid precursor protein by $\alpha$-secretase occurs at the surface of neuronal cells. Biochemistry 38, 9728-9734, doi:10.1021/bi9906827 (1999).

27. Skovronsky, D. M., Moore, D. B., Milla, M. E., Doms, R. W. \& Lee, V. M. Protein kinase C-dependent alpha-secretase competes with beta-secretase for cleavage of amyloid-beta precursor protein in the trans-Golgi network. J Biol Chem 275, 2568-2575, doi:10.1074/ jbc.275.4.2568 (2000).

28. Gutwein, P. et al. ADAM10-mediated cleavage of $\mathrm{L} 1$ adhesion molecule at the cell surface and in released membrane vesicles. FASEB J 17, 292-294, doi:10.1096/fj.02-0430fje (2003).

29. Chasseigneaux, S. \& Allinquant, B. Functions of A $\beta$, sAPP $\alpha$ and sAPP $\beta$ : similarities and differences. J Neurochem 120(Suppl 1), 99-108, doi:10.1111/j.1471-4159.2011.07584.x (2012).

30. Hasebe, N., Fujita, Y., Ueno, M., Yoshimura, K., Fujino, Y. \& Yamashita, T. Soluble $\beta$-amyloid precursor protein alpha binds to p75 neurotrophin receptor to promote neurite outgrowth. PLoS One 8, e82321, doi:10.1371/journal.pone.0082321 (2013).

31. Olsson, A. et al. Measurement of alpha- and beta-secretase cleaved amyloid precursor protein in cerebrospinal fluid from Alzheimer patients. Exp Neurol 183, 74-80, doi:10.1016/S0014-4886(03)00027-X (2003).

32. Endres, K. \& Fahrenholz, F. Upregulation of the alpha-secretase ADAM10-risk or reason for hope? FEBS J 277, 1585-1596, doi:10.1111/j.1742-4658.2010.07566.x (2010).

33. Furukawa, K. \& Mattson, M. P. Secreted amyloid precursor protein alpha selectively suppresses N-methyl-D-aspartate currents in hippocampal neurons: involvement of cyclic GMP. Neuroscience 83, 429-438, doi:10.1016/S0306-4522(97)00398-9 (1998).

34. Goodman, Y. \& Mattson, M. P. Secreted forms of beta-amyloid precursor protein protect hippocampal neurons against amyloid beta-peptide-induced oxidative injury. Exp Neurol 128, 1-12, doi:10.1006/exnr.1994.1107 (1994).

35. Gralle, M., Botelho, M. G. \& Wouters, F. S. Neuroprotective secreted amyloid precursor protein acts by disrupting amyloid precursor protein dimers. J Biol Chem 284, 15016-15025, doi:10.1074/jbc.M808755200 (2009).

36. Han, P. et al. Suppression of cyclin-dependent kinase 5 activation by amyloid precursor protein: a novel excitoprotective mechanism involving modulation of tau phosphorylation. J Neurosci 25, 11542-11552, doi:10.1523/JNEUROSCI.3831-05.2005 (2005).

37. Roch, J. M. et al. Increase of synaptic density and memory retention by a peptide representing the trophic domain of the amyloid beta/A4 protein precursor. Proc Natl Acad Sci USA 91, 7450-7454, doi:10.1073/pnas.91.16.7450 (1994).

38. Park, H. J. et al. Retention in endoplasmic reticulum 1 (RER1) modulates amyloid- $\beta$ (A $\beta$ ) production by altering trafficking of $\gamma$-secretase and amyloid precursor protein (APP). J Biol Chem 287, 40629-40640, doi:10.1074/jbc.M112.418442 (2012).

39. Saraceno, C. et al. SAP97-mediated ADAM10 trafficking from Golgi outposts depends on PKC phosphorylation. Cell Death Dis 5, e1547, doi:10.1038/cddis.2014.492 (2014).

40. Vassar, R. et al. Beta-secretase cleavage of Alzheimer's amyloid precursor protein by the transmembrane aspartic protease BACE. Science 286, 735-741, doi:10.1126/science.286.5440.735 (1999).

41. Laird, F. M. et al. BACE 1, a major determinant of selective vulnerability of the brain to amyloid-beta amyloidogenesis, is essential for cognitive, emotional, and synaptic functions. J Neurosci 25, 11693-11709, doi:10.1523/JNEUROSCI.2766-05.2005 (2005)

42. Zhao, J. et al. Beta-secretase processing of the beta-amyloid precursor protein in transgenic mice is efficient in neurons but inefficient in astrocytes. J Biol Chem 271, 31407-31411, doi:10.1074/jbc.271.49.31407 (1996).

43. Takami, M. \& Funamoto, S. $\gamma$-secretase-dependent proteolysis of transmembrane domain of amyloid precursor protein: successive tri- and tetrapeptide release in amyloid $\beta$-protein production. Int J Alzheimers Dis 2012, 591392-7, doi:10.1155/2012/591392 (2012). 
44. Mizuno, T. The biphasic role of microglia in Alzheimer's disease. Int J Alzheimers Dis 2012, 737846-9, doi:10.1155/2012/737846 (2012).

45. Heneka, M. T., Rodriguez, J. J. \& Verkhratsky, A. Neuroglia in neurodegeneration. Brain Res Rev 63, 189-211, doi:10.1016/j. brainresrev.2009.11.004 (2010).

46. Araque, A. \& Navarrete, M. Glial cells in neuronal network function. Philos Trans R Soc Lond B Biol Sci 365, 2375-2381, doi:10.1098/ rstb.2009.0313 (2010).

47. Giaume, C., Koulakoff, A., Roux, L., Holcman, D. \& Rouach, N. Astroglial networks: a step further in neuroglial and gliovascular interactions. Nat Rev. Neurosci 11, 87-99, doi:10.1038/nrn2757 (2010).

48. Halassa, M. M. \& Haydon, P. G. Integrated brain circuits: astrocyte networks modulate neuronal activity and behavior. Annu Rev Physiol 72, 335-355, doi:10.1146/annurev-physiol-021909-135843 (2010).

49. Mulder, S. D., Veerhuis, R., Blankenstein, M. A. \& Nielsen, H. M. The effect of amyloid associated proteins on the expression of genes involved in amyloid- $\beta$ clearance by adult human astrocytes. Exp Neurol 233, 373-379, doi:10.1016/j.expneurol.2011.11.001 (2012).

50. Blasko, I., Veerhuis, R., Stampfer-Kountchev, M., Saurwein-Teissl, M., Eikelenboom, P. \& Grubeck-Loebenstein, B. Costimulatory effects of interferon-gamma and interleukin-1beta or tumor necrosis factor alpha on the synthesis of Abeta1-40 and Abeta1-42 by human astrocytes. Neurobiol Dis 7(6 Pt B), 682-689, doi:10.1006/nbdi.2000.0321 (2000).

51. Zhao, J., O'Connor, T. \& Vassar, R. The contribution of activated astrocytes to $A \beta$ production: implications for Alzheimer's disease pathogenesis. J Neuroinflammation 8, 150, doi:10.1186/1742-2094-8-150 (2011).

52. Dal Prà, I. et al. The amyloid- $\beta 42$ proxy, amyloid- $\beta 25-35$, induces normal human cerebral astrocytes to produce amyloid- $\beta 42$. J Alzheimer's Dis 24, 335-347, doi:10.3233/JAD-2011-101626 (2011).

53. Dal Prà, I. et al. Calcium-sensing receptors of human astrocyte-neuron teams: Amyloid-beta-driven mediators and therapeutic targets of Alzheimer's Disease. Curr Neuropharmacol 12, 353-364, doi:10.2174/1570159X12666140828214701 (2014).

54. Nemeth, E. F. \& Goodman, W. G. Calcimimetic and calcilytic drugs: feats, flops, and futures. Calcif Tissue Int 98, 341-358, doi:10.1007/s00223-015-0052-z (2015).

55. Chakravarty, B., Chattopadhyay, N. \& Brown, E. M. Signaling through the extracellular calcium-sensing receptor (CaSR). Adv Exp Med Biol 740, 103-142, doi:10.1007/978-94-007-2888-2_5 (2012).

56. Zhang, C., Miller, C. L., Brown, E. M. \& Yang, J. J. The calcium sensing receptor: from calcium sensing to signaling. Sci China Life Sci 58, 14-27, doi:10.1007/s11427-014-4779-y (2015).

57. Bandyopadhyay, S., Tfelt-Hansen, J. \& Chattopadhyay, N. Diverse roles of extracellular calcium-sensing receptor in the central nervous system. J Neurosci Res 88, 2073-2082, doi:10.1002/jnr.22391 (2010).

58. Dal Prà, I., Chiarini, A., Nemeth, E. F., Armato, U. \& Whitfield, J. F. Roles of the Ca2+-sensing receptor (CaSR) in the expression of inducible NOS (nitric oxide synthase)-2 and its BH4 (tetrahydrobiopterin)-dependent activation in cytokine-stimulated adult human astrocytes. J Cell Biochem 96, 428-438, doi:10.1002/jcb.20511 (2005).

59. Riccardi, D. \& Kemp, P. J. The calcium-sensing receptor beyond extracellular calcium homeostasis: conception. development, adult physiology, and disease. Annu Rev Physyiol 74, 271-297, doi:10.1146/annurev-physiol-020911-153318 (2012).

60. Armato, U. et al. The calcium-sensing receptor: a novel Alzheimer's disease crucial target? J Neurol Sci 322, 137-140, doi:10.1016/j. jns.2012.07.031 (2012).

61. Dal Prà, I. et al. The Abeta peptides-activated calcium-sensing receptor stimulates the production and secretion of vascular endothelial growth factor-A by normoxic adult human cortical astrocytes. Neuromolecular Med 16, 645-657, doi:10.1007/s12017014-8315-9 (2014)

62. Kim, J. Y., Ho, H., Kim, N., Liu, J., Yenari, M. A. \& Wenhan, C. Calcium- sensing receptor (CaSR): a novel target for ischemic neuroprotection. Ann Clin Transl Neurol 1, 851-866, doi:10.1002/acn3.118 (2014).

63. Bai, S. et al. Calcium sensing receptor mediated the excessive generation of beta-amyloid peptide induced by hypoxia in vivo and in vitro. Biochem Biophys Res Commun 459, 568-573, doi:10.1016/j.bbrc.2015.02.141 (2015).

64. Davey, A. E., Leach, K., Valant, C., Conigrave, A. D., Sexton, P. M. \& Christopolous, A. Positive and negative allosteric modulators promote biased signaling at the calcium-sensing receptor. Endocrinology 153, 4304-4316, doi:10.1210/en.2011-1426 (2012).

65. Schöll, M. et al. Early astrocytosis in autosomal dominant Alzheimer's disease measured in vivo by multi-tracer positron emission tomography. Sci Rep. 5, 16404, doi:10.1038/srep16404 (2015).

66. Thinakaran, G. \& Koo, E. H. Amyloid precursor protein trafficking, processing, and function. J Biol Chem 283, 29615-29619, doi:10.1074/jbc.R800019200 (2008).

67. Haass, C., Koo, E. H., Capell, A., Teplow, D. B. \& Selkoe, D. J. Polarized sorting of beta-amyloid precursor protein and its proteolytic products in MDCK cells is regulated by two independent signals. J Cell Biol 128, 537-547, doi:10.1083/jcb.128.4.537 (1995).

68. Jiang, S., Li, Y., Zhang, X., Bu, G., Xu, H. \& Zhang, Y. W. Trafficking regulation of proteins in Alzheimer's disease. Mol Neurodegener 9, 6, doi:10.1186/1750-1326-9-6 (2014).

69. Haas, C., Kaether, C., Thinakaran, G. \& Sisodia, S. Trafficking and proteolytic processing of APP. Cold Spring Harb Perspect Med 2, a006270 (2012)

70. Postina, R. et al. A disintegrin-metalloproteinase prevents amyloid plaque formation and hippocampal defects in an Alzheimer disease mouse model. J Clin Invest 113, 1456-1464, doi:10.1172/JCI20864 (2004).

71. Saftig, P. \& Lichtenthaler, S. F. The alpha secretase ADAM10: A metalloprotease with multiple functions in the brain. Progress Neurobiol 135, 1-20, doi:10.1016/j.pneurobio.2015.10.003 (2015).

72. Anders, A., Gilbert, S., Garten, W., Postina, R. \& Fahrenholz, F. Regulation of the alpha-secretase ADAM10 by its prodomain and proprotein convertases. FASEB J 15, 1837-1839, doi:10.1096/fi.01-0007fje (2001).

73. Jorissen, E. et al. The disintegrin/metalloproteinase ADAM10 is essential for the establishment of the brain cortex. J Neurosci 30, 4833-4844, doi:10.1523/JNEUROSCI.5221-09.2010 (2010).

\section{Acknowledgements}

This work was supported by the Italian Ministry of Education, University, and Research FUR Fund 2014 to A.C. and I.D.P. The funding Institution played no role in the study design, data collection and analysis, decision to publish, or preparation of the manuscript.

\section{Author Contributions}

A.C., U.A., and I.D.P. conceived the research and designed the experiments. D.L., A.C., and I.D.P. performed the experiments and collected the results. U.A., and D.L. statistically analysed the data. A.C., U.A. and I.D.P. interpreted the results. The manuscript was principally written and revised by U.A., A.C. and I.D.P. All the authors critically reviewed the manuscript for important intellectual content and approved the final submitted manuscript.

\section{Additional Information}

Supplementary information accompanies this paper at doi:10.1038/s41598-017-01215-3 
Competing Interests: The authors declare that they have no competing interests.

Publisher's note: Springer Nature remains neutral with regard to jurisdictional claims in published maps and institutional affiliations.

(c) (i) Open Access This article is licensed under a Creative Commons Attribution 4.0 International License, which permits use, sharing, adaptation, distribution and reproduction in any medium or format, as long as you give appropriate credit to the original author(s) and the source, provide a link to the Creative Commons license, and indicate if changes were made. The images or other third party material in this article are included in the article's Creative Commons license, unless indicated otherwise in a credit line to the material. If material is not included in the article's Creative Commons license and your intended use is not permitted by statutory regulation or exceeds the permitted use, you will need to obtain permission directly from the copyright holder. To view a copy of this license, visit http://creativecommons.org/licenses/by/4.0/.

(C) The Author(s) 2017 